\title{
Gene Dosage in the Dysbindin Schizophrenia Susceptibility Network Differentially Affect Synaptic Function and Plasticity
}

\author{
Ariana P. Mullin, ${ }^{1}$ Madhumala K. Sadanandappa, ${ }^{2}$ Wenpei Ma, ${ }^{3}$ Dion K. Dickman, ${ }^{3}$ Krishnaswamy VijayRaghavan, ${ }^{2}$ \\ Mani Ramaswami, ${ }^{4}$ Subhabrata Sanyal, ${ }^{5}$ and Victor Faundez ${ }^{1,6}$ \\ ${ }^{1}$ Department of Cell Biology, Emory University, Atlanta, Georgia 30322, ${ }^{2}$ National Centre for Biological Sciences, Bangalore 560065, India, ${ }^{3}$ Department of \\ Biology, Neurobiology Section, University of Southern California, Los Angeles, California 90089, ${ }^{4}$ School of Genetics and Microbiology, School of Natural \\ Sciences, Smurfit Institute of Genetics and Trinity College Institute of Neuroscience, Trinity College Dublin, Dublin-2, Ireland, ${ }^{5}$ Biogen-Idec, Cambridge, \\ Massachusetts 02142, and ${ }^{6}$ Center for Social Translational Neuroscience, Emory University, Atlanta, Georgia 30322
}

\begin{abstract}
Neurodevelopmental disorders arise from single or multiple gene defects. However, the way multiple loci interact to modify phenotypic outcomes remains poorly understood. Here, we studied phenotypes associated with mutations in the schizophrenia susceptibility gene dysbindin (dysb), in isolation or in combination with null alleles in the $d y s b$ network component Blos 1 . In humans, the Blos 1 ortholog Bloc1s1 encodes a polypeptide that assembles, with dysbindin, into the octameric BLOC-1 complex. We biochemically confirmed BLOC-1 presence in Drosophila neurons, and measured synaptic output and complex adaptive behavior in response to BLOC-1 perturbation. Homozygous loss-of-function alleles of $d y s b$, Blos 1 , or compound heterozygotes of these alleles impaired neurotransmitter release, synapse morphology, and homeostatic plasticity at the larval neuromuscular junction, and impaired olfactory habituation. This multiparameter assessment indicated that phenotypes were differentially sensitive to genetic dosages of loss-of-function BLOC-1 alleles. Our findings suggest that modification of a second genetic locus in a defined neurodevelopmental regulatory network does not follow a strict additive genetic inheritance, but rather, precise stoichiometry within the network determines phenotypic outcomes.
\end{abstract}

Key words: BLOC-1; dysbindin; olfactory habituation; schizophrenia; synaptic vesicle

\section{Introduction}

Multiple gene products converge into molecular and functional networks to influence neuronal traits, ranging from simple synapse mechanisms to complex behaviors (Kendler and Greenspan, 2006). These networks have been studied through single gene disruptions, which provide fundamental insight into the necessity and sufficiency of a single gene product for a neuronal phenotype. However, these studies assume that gene products organize into linear pathways that remain stable following disruption of a single gene, rather than dynamic networks (Greenspan, 2009). This approach is at odds with the genetics of neurodevelopmental disorders, where

\footnotetext{
Received Aug. 24, 2014; revised 0ct. 16, 2014; accepted Nov. 11, 2014.

Author contributions: A.P.M., M.K.S., D.K.D., K.V., M.R.,S.S., and V.F. designed research;A.P.M., M.K.S., M.R., and S.S. performed research; W.M., D.K.D., K.V., and M.R. contributed unpublished reagents/analytic tools; A.P.M., M.K.S., K.V., M.R., S.S., and V.F. analyzed data; A.P.M., M.R., S.S., and V.F. wrote the paper.

This work was supported by grants from the National Institutes of Health (GM077569) and in part by the Emory University Integrated Cellular Imaging Microscopy Core and Viral Cores of the Emory Neuroscience National Institute of Neurological Disorders and Stroke Core Facilities Grant (P30NS055077 to V.F.) and grants from Science Foundation Ireland to M.R., Core funds from the NCBS TIFR Centre to K.V., and an INSPIRE fellowship from Department of Science and Technology India and Biocon India Scholarship Programme to M.K.S. We thank Isabell Twick for making the "clean" dysb1 line used here and Raheleh Heidari for valuable preliminary studies of STH in dysb1 mutants. We are indebted to the Faundez lab members for their comments.

The authors declare no competing financial interests.

Correspondence should be addressed to Victor Faundez, 615 Michael Street, Whitehead Room 446, Atlanta, GA 30322.E-mail: vfaunde@emory.edu.

DOI:10.1523/JNEUROSCI.3542-14.2015

Copyright $\odot 2015$ the authors $\quad 0270-6474 / 15 / 350325-14 \$ 15.00 / 0$
}

complex phenotypes emerge from the simultaneous modification of several genes (Stefansson et al., 2009, 2014; Bassett et al., 2010; Malhotra and Sebat, 2012; Rapoport et al., 2012; Moreno-De-Luca et al., 2013). This raises the question of how two or more genes interact to specify neuronal traits.

Here we model a two-loci genetic deficiency affecting a schizophrenia susceptibility network centered on the human gene DTNBP1 and its Drosophila ortholog dysb, both of which encode Dysbindin. We previously defined the human Dysbindin interactome (Gokhale et al., 2012), the core of which is comprised of Dysbindin and seven closely associated proteins that form an octameric complex known as the biogenesis of lysosome-related organelles complex 1 (BLOC-1; Ghiani and Dell'Aangelica, 2011; Gokhale et al., 2012; Mullin et al., 2013). Polymorphisms in DTNBP1 are risk factors for schizophrenia (Gornick et al., 2005; Talbot et al., 2009; Fatjó-Vilas et al., 2011; Mullin et al., 2011) and influence cognitive and neuroanatomical traits (Mullin et al., 2011; Ghiani and Dell'Angelica, 2011; Papaleo et al., 2014). Postmortem analysis revealed that $80 \%$ of schizophrenia brains contain reduced dysbindin (Talbot et al., 2004). The association of Dysbindin with schizophrenia and its inclusion into the biochemically defined BLOC-1 network suggest that combined loss-of-function mutations affecting dysbindin and the BLOC-1 network should generate predictable synaptic and circuit phenotypes, reminiscent of those in copy number variations associated with neurodevelopmental disorders. 
We used Drosophila to understand the impact of fly loss-offunction mutations affecting BLOC-1 orthologous subunits on synaptic networks (Cheli et al., 2010). We predicted that phenotypes associated with gene copy reductions affecting BLOC-1 subunits should follow a recessive inheritance pattern, as has previously been described for BLOC-1 (Cheli et al., 2010), and that this pattern should be congruent across synaptic mechanisms that progressively scale up in complexity. We tested neurotransmitter release, synapse morphology, homeostatic plasticity, and behavioral/olfactory habituation in four BLOC-1 loss-of-function genotypes. Contrary to our prediction, homozygous loss-offunction alleles of BLOC-1 subunit genes dysb or Blos 1 , or compound heterozygotes in the two genes, affected synaptic functions with divergent inheritance patterns rather than the predicted simple recessive pattern. We conclude that single synapse and circuit-based phenotypes associated with a single gene-dosage imbalance are noncongruently modified by a second locus encoding an interactome component. We propose that genetic control of the stoichiometry of a neurodevelopmental regulatory network diversifies phenotypic output in normal and disease states.

\section{Materials and Methods}

Drosophila stocks, rearing, genetics, and electrophysiology. All fly stocks were reared and maintained at $25^{\circ} \mathrm{C}$ on normal media. For crosses, standard second and third chromosome balancers were used. $d y s b^{1}$, UASDysb, UAS-Venus-dysbindin, $d y s b^{r v}$, and $d y s b^{D f}$ were obtained from Graeme Davis (University of California, San Francisco); blos $1^{e x 2}$, blos $1^{\text {ex65 }}$ and UAS-blos1 were obtained from Esteban Dell'Angelica (University of California, Los Angeles; Cheli et al., 2010). $w^{1118}$, Canton S, Elav-GAL4 ${ }^{\mathrm{C} 155}$, and other fly strains such as balancer chromosomecontaining and tissue-specific Elav-GAL4 driver stocks are part of the Sanyal or Ramaswami laboratory collection. Blos $1^{E Y}$ was obtained from Bloomington Drosophila Stock Center and UAS-dysb RNAi was from National Institute of Genetics.

For all physiological intracellular recordings, data were obtained from muscle 6 of abdominal segment 2 or 3 of female, wandering third-instar larvae. Recordings were only used if the resting membrane potential was between -60 and $-90 \mathrm{mV}$ and the muscle input resistance was $>5 \mathrm{M} \Omega$. For miniature excitatory junctional potential (mEJP) analysis and philanthotoxin experiments, intracellular recordings were performed in modified HL3 saline containing the following (in $\mathrm{mM}$ ): $70 \mathrm{NaCl}, 5 \mathrm{KCl}$, $0.3 \mathrm{CaCl}_{2}, 1.0 \mathrm{MgCl}_{2}, 10 \mathrm{NaHCO}_{3}, 115$ sucrose, 5 trehalose, and $5 \mathrm{BES}$, $\mathrm{pH}$ 7.2. Severed motor neurons were taken up into a stimulating electrode and stimulated at $1 \mathrm{~Hz}$ for $50 \mathrm{~s}$. For acute pharmacological homeostatic challenge, experiments were conducted as previously described (Dickman and Davis, 2009; Dickman et al., 2012). Briefly, semi-intact preparations were maintained with the CNS, fat, and gut intact and perfused with phillanthatoxin-433 (PhTx; Sigma). A stock solution of PhTx was prepared ( $4 \mathrm{~mm}$ in DMSO) and diluted for use to $4 \mu \mathrm{M}$ in modified HL3. Preparations were incubated for $10 \mathrm{~min}$ in $\mathrm{PhTx}$, rinsed in modified HL3, and dissections were then completed. Recordings were only used if the mEJP amplitude following toxin incubation was $\leq 60 \%$ of baseline $\mathrm{mEJP}$ amplitude, indicative of the toxin gaining access to the muscle.

For vesicle pool separation experiments, physiological recordings were performed in normal HL3 containing the following (in $\mathrm{mM}$ ): $70 \mathrm{NaCl}, 5$ $\mathrm{KCl}, 1.0 \mathrm{CaCl}_{2}, 2.0 \mathrm{MgCl}_{2}, 10 \mathrm{NaHCO}_{3}, 115$ sucrose, 5 trehalose, and 5 $\mathrm{BES}, \mathrm{pH}$ 7.2. Before stimulation, animals were dissected in $\mathrm{Ca}^{2+}$-free HL3 and incubated in $1 \mu \mathrm{M}$ bafilomycin A1 for $15 \mathrm{~min}$. After incubation, severed motor neurons were taken up into a stimulating electrode and stimulated for $30 \mathrm{~min}$ at either $3 \mathrm{~Hz}$ (low frequency) or $10 \mathrm{~Hz}$ (high frequency) in the presence of $1 \mu \mathrm{m}$ bafilomycin A1 (Sigma-Aldrich, catalog \#B1793). Bafilomycin A1 was prepared as a $1 \mathrm{~mm}$ stock solution in DMSO and diluted for us at $1 \mu \mathrm{M}$ in normal HL3. Semi-intact preparations were prepared as described previously (Kim et al., 2009).

For all electrophysiological experiments, a magnetic glass microelectrode horizontal puller ( $\mathrm{PN}-30$; Narishige) was used to prepare microelectrodes (30-70 M $\Omega$ resistance, backfilled with $3 \mathrm{M} \mathrm{KCl}$ ). Amplification of signals was achieved using Axoclamp 900A. Signals were digitized using Digidata 1440A and recorded using Clampfit 10.1. Analysis was done in Mini Analysis (Synaptosoft) and Microsoft Excel. For baseline-evoked responses and homeostasis assays, the average EJP was divided by the average mEJP to determine quantal content. For low- and high-frequency stimulation protocols, quantal content for each stimulated response was calculated, and then normalized as a percentage of the first recorded response. Tau was calculated for the stimulation to $50 \%$ decay of initial response. Nonlinear summation correction was applied across all quantal content calculations.

Immunohistochemistry, microscopy, and synaptic vesicle size determinations. Larval dissections, immunohistochemistry, and confocal microscopy were conducted as previously described (Franciscovich et al., 2008). Wandering third-instar female larvae were dissected in normal HL3, fixed in $4 \%$ paraformaldehyde for $1 \mathrm{~h}$, and stained with HRP-FITC for $2 \mathrm{~h}$ at room temperature (1:500). An inverted 510 Zeiss LSM microscope was used for confocal imaging. At least 15 animals were counted per genotype.

Quantitative electron microscopy of presynaptic terminals was performed as previously reported (Pielage et al., 2005). Briefly, pinned out larvae were fixed with $2 \%$ glutaraldehyde in $0.12 \mathrm{M} \mathrm{Na}$-cacodylate buffer, $\mathrm{pH} 7.4$, and postfixed with $1 \%$ osmium tetroxide in $0.12 \mathrm{M} \mathrm{Na}$ cacodylate. Larvae were en bloc stained with $1 \%$ aqueous uranyl acetate for thin sectioning and imaging for synaptic vesicle morphometry as described previously (Heerssen et al., 2008). Synaptic vesicle sizes were assessed by glycerol velocity sedimentation of high-speed head extract supernatants as described previously (van de Goor et al., 1995). Heads were collected from adult males and females as described below. Vesiclecontaining fractions were detected with antibodies against csp obtained from The Developmental Studies Hybridoma Bank at University of Iowa.

Immunoprecipitation and MS. To determine interactions between Drosophila BLOC-1 subunits, fly heads from adult males and females were prepared as previously described (Roos and Kelly, 1998). Briefly, for each genotype, $\sim 100$ animals were flash frozen in liquid nitrogen and heads were separated then collected by passing the frozen tissue through a microsieve in liquid nitrogen. The frozen tissue was ground into a powder using a mortar and pestle, and combined with $100 \mu$ lysis (Buffer A: $150 \mathrm{~mm} \mathrm{NaCl}, 10 \mathrm{~mm}$ HEPES, $1 \mathrm{~mm}$ EGTA, and $0.1 \mathrm{~mm} \mathrm{MgCl}_{2}, \mathrm{pH} 7.4$ $+0.5 \%$ Triton X-100) with Complete anti-protease (catalog \#11245200; Roche), and also frozen and ground into a powder and stored at $-80^{\circ} \mathrm{C}$. Samples were thawed and sonicated, tissue debris was removed by centrifugation, and protein concentration determined by Bradford assay (Bio-Rad). Proteins were resolved by SDS-PAGE on a $4-20 \%$ gel (Invitrogen) and immunoblot analysis was performed as previously described (Gokhale et al., 2012; Ryder et al., 2013). Dyna magnetic beads (catalog \#110.31; Invitrogen) were coated with anti-GFP monoclonal (Lifesciences Molecular Probes, catolog \#A11120) and incubated for $2 \mathrm{~h}$ at $4^{\circ} \mathrm{C}$ with $500 \mu \mathrm{g}$ of protein extract. The beads were then washed four to six times with Buffer A ( $0.1 \%$ Triton X-100). Proteins were eluted with Laemmli sample buffer at $75^{\circ} \mathrm{C}$. Samples were either resolved by SDSPAGE and contents analyzed by immunoblot, or processed for MS protein identification by MS Bioworks as described previously (Gokhale et al., 2012; Ryder et al., 2013).

Short-term olfactory habituation. Short-term olfactory habituation was tested using a Y-maze apparatus as previously described (Das et al., 2011; Sadanandappa et al., 2013). Briefly, 4-d-old adult male and female flies were starved overnight and the naive response to ethyl butyrate (EB; $10^{-3}$ dilution in water) was tested (pre-test response). To induce shortterm habituation (STH), flies were then transferred to a $125 \mathrm{ml}$ glass bottle containing a suspended, 1.5 mlEppendorf with 5\% EB in paraffin oil with the lid perforated for $30 \mathrm{~min}$. Animals were then tested for response following the $30 \mathrm{~min}$ period (post-test response). For conditional dysbindin knockdown experiments parental flies were reared at $18^{\circ} \mathrm{C}$ till eclosion. Newly eclosed flies $(0-12 \mathrm{~h})$ were shifted to $29^{\circ} \mathrm{C}$, whereas the control flies were maintained at $18^{\circ} \mathrm{C}$. After $4 \mathrm{~d}$, flies were subjected to STH protocol, as described above.

Statistical and cluster analysis. Experimental conditions were compared using Synergy KaleidaGraph, version 4.1.3 or StatPlus Mac Built 
A

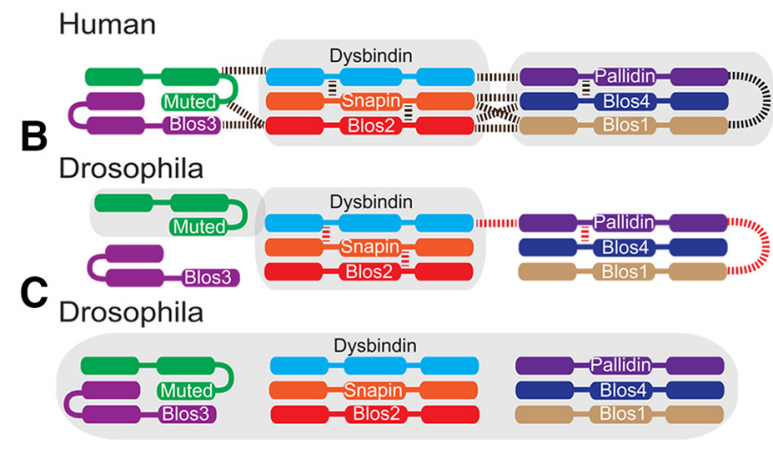

D

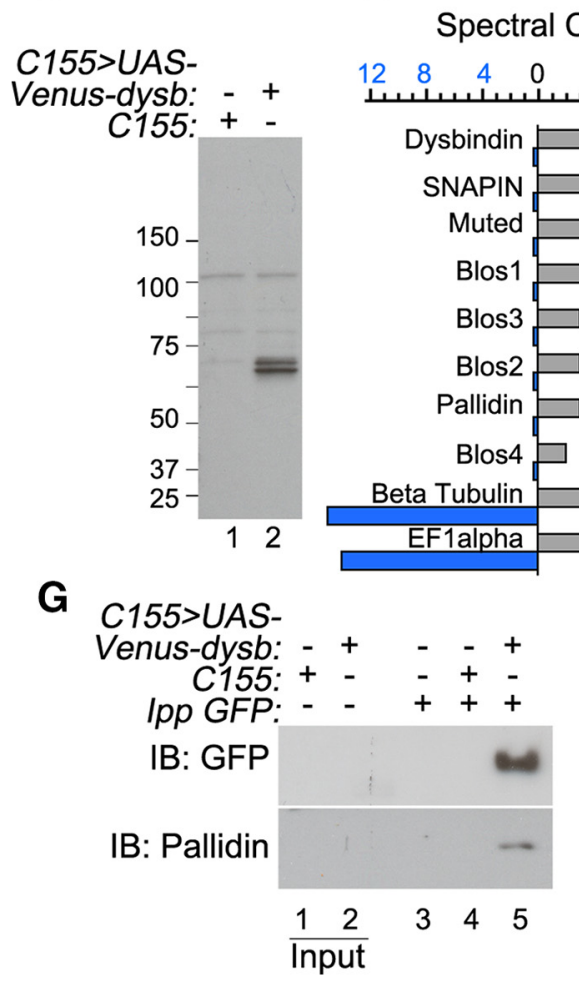

H
$\mathbf{F}$
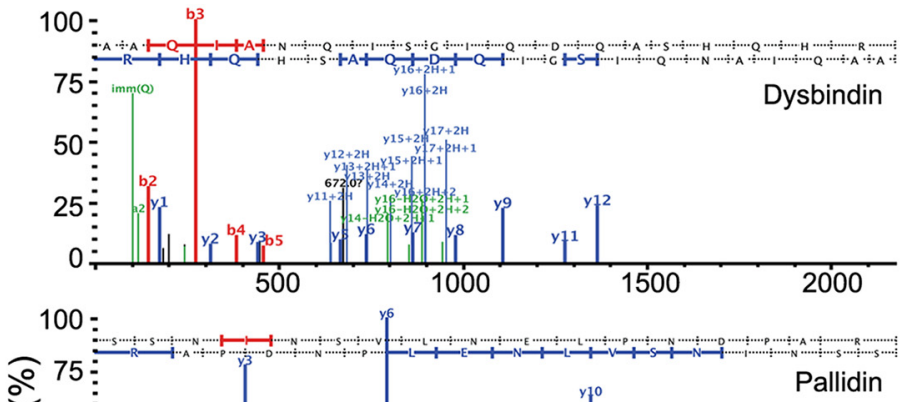

allidin
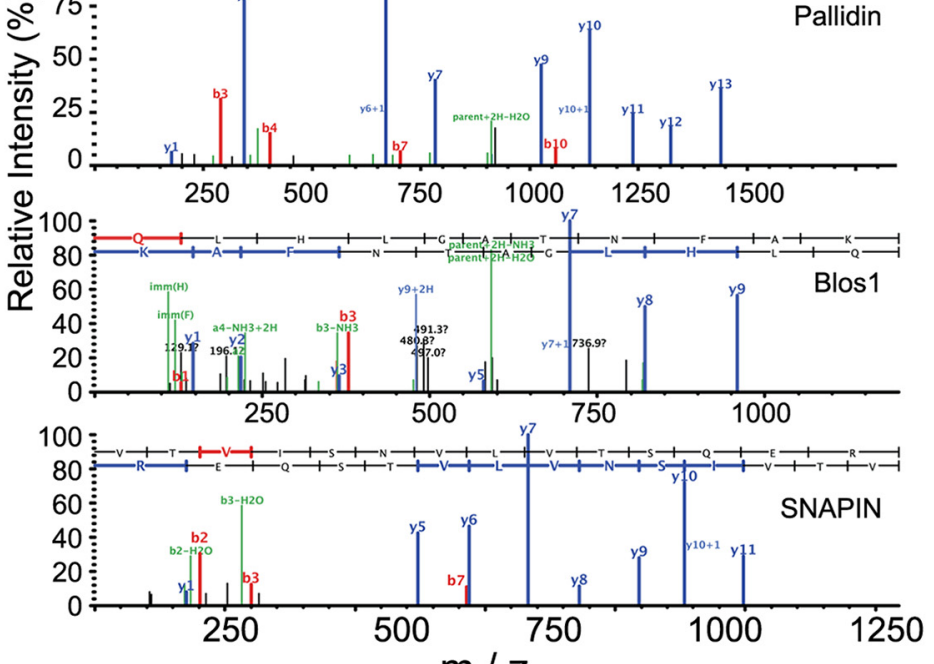

$\mathrm{m} / \mathrm{z}$
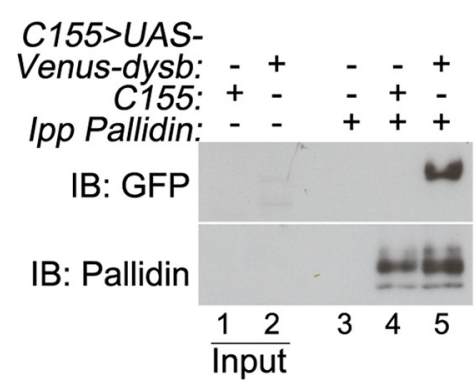

Figure 1. BLOC-1 assembles into an octameric complex in Drosophila neurons. Previously identified mammalian $(\boldsymbol{A})$ and Drosophila (B) BLOC-1 subunit interactions. Dotted lines represent interactions identified by yeast two-hybrid (dotted lines), while shaded regions depict complex or subcomplex formation based on immunoprecipitation or cosedimentation studies. Identification of Drosophila BLOC-1 subunits immunoprecipitating Venus-Dysbindin is consistent with octameric mammalian BLOC-1 architecture (C). Immunoblot with GFP antibodies confirms expression of the Venus-Dysbindin transgene from fly head lysates in animals expressing the transgene (lane 2) but not control animals (lane 1; D). Lysates as shown in $\boldsymbol{D}$ were immunoprecipitated using GFP antibodies. Spectral counts of all eight BLOC-1 subunit orthologs were selectively enriched following immunoprecipitation with GFP antibodies from animals expressing the Venus-Dysbindin transgene ( $\boldsymbol{E}$, gray bars) compared with controls ( $\boldsymbol{E}$, blue bars). Proteins nonspecifically bound to the GFP beads such as $\beta$-tubulin and elongation factor $1 \alpha$ (EF1 $\alpha$ ) were represented with similar spectral counts in both samples $(\boldsymbol{E})$. MS/MS peptide sequencing of select immunoprecipitated Drosophila BLOC-1 subunit orthologs $(\boldsymbol{F})$. Specific detection of BLOC-1 ortholog Pallidin by immunoblot in Venus-Dysbindin-expressing fly head lysates immunoprecipitated with GFP antibodies (G, lane 5). Pallidin antibodies precipitate Venus-Dysbindin from Venus-Dysbindin-expressing fly head lysates detected with GFP antibodies ( $\boldsymbol{H}$, lane 5).

5.6.0pre/Universal (AnalystSoft). Tests are indicated in each figure. Cluster analysis was performed with Cluster 3.0 (http://rana.lbl.gov/ EisenSoftware.htm; Eisen et al., 1998) and visualized using TreeView-1.1.6r4. Random genotype-phenotype pairs were generated with the engine www.random.org.

\section{Results}

BLOC-1 assembles into an octameric complex in Drosophila neurons

Dysbindin exists as a member of the octameric BLOC-1 in mammalian cells (Fig. 1A). While all eight mammalian BLOC-1 subunits have Drosophila orthologs, the existence of this complex in
Drosophila has not yet been established, but has been predicted from yeast two-hybrid and proteomic studies (Cheli et al., 2010; Guruharsha et al., 2011). However, these studies only document a subset of the predicted interactions among the eight Drosophila BLOC-1 subunit orthologs (Fig. 1B). Thus, we first set out to determine whether an orthologous Dysbindin-containing BLOC-1 complex assembles in the Drosophila CNS neurons (Fig. 1C). We focused on this cell type based on previous work documenting the localization and requirement of Dysbindin to the presynaptic compartment (Dickman and Davis, 2009). To do this, we used Dysbindin as bait to immunoprecipitate Dysbindin and associ- 
ated proteins from fly head lysates. UAS-Venus-tagged Dysbindin transgene was expressed under the pan-neuronal C155-GAL4 driver to identify neuronal proteins coprecipitating with recombinant Dysbindin in Drosophila. We prepared detergent-soluble tissue homogenates from fly heads carrying either the C155 driver alone as controls, or in combination with UAS-VenusDysbindin transgene to express tagged dysbindin (Fig. $1 D$, compare lanes 1 and 2). Venus-tagged Dysbindin from head extracts was immunoprecipitated using a GFP antibody, and immune complexes were profiled by quantitative mass spectrometry. Immunoprecipitation of Venus-Dysbindin enriched all eight BLOC-1 Drosophila orthologs compared with the C155 control, determined by spectral count quantitation (Fig. 1E). The low abundance of these proteins precluded an estimate of stoichiometry based on spectral counts. Proteins nonselectively bound to GFP beads, such as tubulin and elongation factor $1 \alpha$, were similarly represented in spectral counts in both control and VenusDysbindin precipitated samples (Fig. $1 E$ ). The identity of the Drosophila BLOC-1 subunit orthologs was confirmed by MS/MS peptide sequencing (Fig. $1 F$ ). Due to the limited availability of Drosophila BLOC-1 antibodies, we verified the PallidinDysbindin interaction by immunoprecipitation of VenusDysbindin and specific detection of coprecipitating Pallidin by Western blot (Fig. 1G, compare lanes 4 and 5), or by specific detection of Venus-Dysbindin in Pallidin precipitated immune complexes from Drosophila head extracts (Fig. $1 \mathrm{H}$, compare lanes 3 and 5). Our data demonstrate that Dysbindin pulls down all BLOC-1 subunits in Drosophila neurons, and suggest that the architecture of Drosophila BLOC-1 highly resembles that found in the human BLOC-1 complex (Fig. 1C).

\section{BLOC-1 acts presynaptically to regulate quantal content at the neuromuscular junction}

The close biochemical identity of the Drosophila and mammalian BLOC-1 complexes suggests that mutations in Drosophila BLOC-1 subunits should produce recessive, gene dosagedependent phenotypes consistent with the recessive nature of individual BLOC-1 subunit mutations in mammalian cells (Huang et al., 1999; Zhang et al., 2002; Ciciotte et al., 2003; Li et al., 2003; Gwynn et al., 2004; Starcevic and Dell'Angelica, 2004). We analyzed whether gene-dosage reductions in BLOC-1 subunits had the capacity to produce recessive synaptic phenotypes. We used a multiparameter assessment of synaptic functions to progressively test increasing levels of synapse organization, ranging from spontaneous neurotransmitter release to circuit-based learning behavior. We began by measuring the spontaneous and evoked neurotransmitter release at the Drosophila third-instar larval neuromuscular junction (NMJ) synapse in gene-dosage imbalances affecting the BLOC-1 complex subunits Dysbindin and Blos1. The NMJ synapse is sensitive to loss-of-function alleles affecting Drosophila BLOC-1 subunits orthologs (Dickman and Davis, 2009; Dickman et al., 2012). We assessed animals for baseline mEJP amplitude and frequency, evoked EJP amplitude, and quantal content. There were no significant differences in the EJP amplitude across diverse modifications in the gene dosage of $d y s b$, Blos 1, or combinations thereof (Fig. $2 F$, representative traces shown in $A-E)$. Similarly, the different BLOC-1 loss-offunction alleles had no effect on the frequency of mEJPs (Fig. $2 F$ ). Consistent with previous reports by Dickman and Davis (2009) and Dickman et al. (2012), the amplitude of the mEJP was not altered in $d y s b^{1}$ dysbindin mutant synapses compared with two control strains, Canton-S or w1118 (Fig. 2G). In contrast, we found that animals carrying any of three Blos1-null alleles-
$B l o s 1^{E Y}$ (Fig 2A, insert), Blos $1^{\text {ex2 }}$, and Blos $1^{\text {ex65 }}$-had increased mEJP amplitudes and correspondingly lower quantal content compared with both wild-type strains (Fig. $2 H, L, P$, respectively, red traces). While this increase in $\mathrm{mEJP}$ amplitude is in agreement with the initial characterization of $B l o s 1^{e x 2}$, we observed that this phenotype was consistent across all three null alleles (Cheli et al., 2010). Additionally, we found this phenotype to be dominant, as it also was present in single-copy loss of Blos1-null alleles (Fig. $2 H, L, P$, respectively, blue traces). Presynaptic ex-

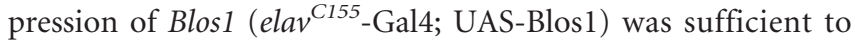
rescue the observed changes in $\mathrm{mEJP}$ amplitude and quantal content (Fig. 2C, K,O). These data demonstrate that Blos1 presynaptically regulates $\mathrm{mEJP}$ amplitude and that this phenotype is a dominant rather than a recessive trait of Blos1-null alleles.

The distinct effect of the Blos1 alleles and lack of effect of the dysbindin alleles on mini amplitude suggested the following two possibilities. First, Blos 1 and dysb participate in different molecular and genetic networks, a hypothesis seemingly at odds with Blos1 and Dysbindin being subunits of the BLOC-1 complex. Second, $d y s b$ alleles reduce BLOC- 1 function to a different extent compared withBlos1-null mutants, suggesting a BLOC-1 complex loss-of-function threshold under which the mEJP phenotype is expressed. To discriminate between these possibilities, we tested the ability of $d y s b$ hypomorphic mutants $\left(d y s b^{1}\right)$ and the deletion $D f(B S C 416$ ), which entirely deletes the dysb gene as well as $\sim 20$ flanking genes (Dickman and Davis, 2009) to genetically interact with Blos1-null alleles in regulating $\mathrm{mEJP}$ amplitude and quantal content at the NMJ. Interestingly, we found that the $d y s b^{1}$ allele expressed in trans with a single-copy loss of Blos1 rescued the $\mathrm{mEJP}$ amplitude and quantal content back to wild-type levels (Fig. 2I,M,Q, compare red and blue traces). We observed the same result in flies double heterozygous for $D f(B S C 416)$ and the $B l o s 1^{E Y}$-null mutation (Fig. 2J, compare red and blue traces). As expected, Blos 1 expressed in trans with the $d y s b^{R V}$, which is a perfect excision of the $d y s b^{1}$ mutation, behaved similar to a single-copy loss of Blos 1 (Fig. 2N, compare red and blue traces). Further, we found that the ability of $d y s b$ alleles to modify Blos 1 $\mathrm{mEJP}$ and resultant quantal content phenotypes is presynaptic, as adding back Dysbindin presynaptically (elav ${ }^{C 155}$-Gal4; UASdysb) in the $B l o s 1^{E Y /+} ; d y s b^{1 /+}$ transheterozygous animal did, in fact, lead to increased mEJP amplitude and reduced quantal content, similar to the effect observed in single-copy loss of Blos 1 (Fig. 2R, compare red and green traces).

The increased mEJP amplitude observed in Blos1-null alleles could result from an increase in synaptic vesicle size. Therefore, we determined synaptic vesicle sizes using glycerol velocity sedimentation of adult head high-speed supernatants (Fig. $3 A$ ) as well as electron microscopy of the larval NMJ (Fig. $3 B-F$ ). We found no differences in synaptic vesicle sizes in Blos1-null animals compared with controls (Fig. $3 A, B$ ) or $B l o s 1^{E Y /+} ; d y s b^{1 /+}$ animals (Fig. $3 A$ ) that display normal amplitude mEJPs. From this, we conclude that the mEJP data demonstrate that BLOC-1 subunits participate in a common presynaptic molecular and genetic network to regulate baseline neurotransmission at the Drosophila NMJ in a manner independent from vesicle size. Additionally, these data show that neurotransmission is sensitive to the genetic dosage and precise stoichiometry of BLOC-1 subunits Dysbindin and Blos1 rather than an additive genetic effect of sequential reduction of individual subunits predicted from a recessive trait. 

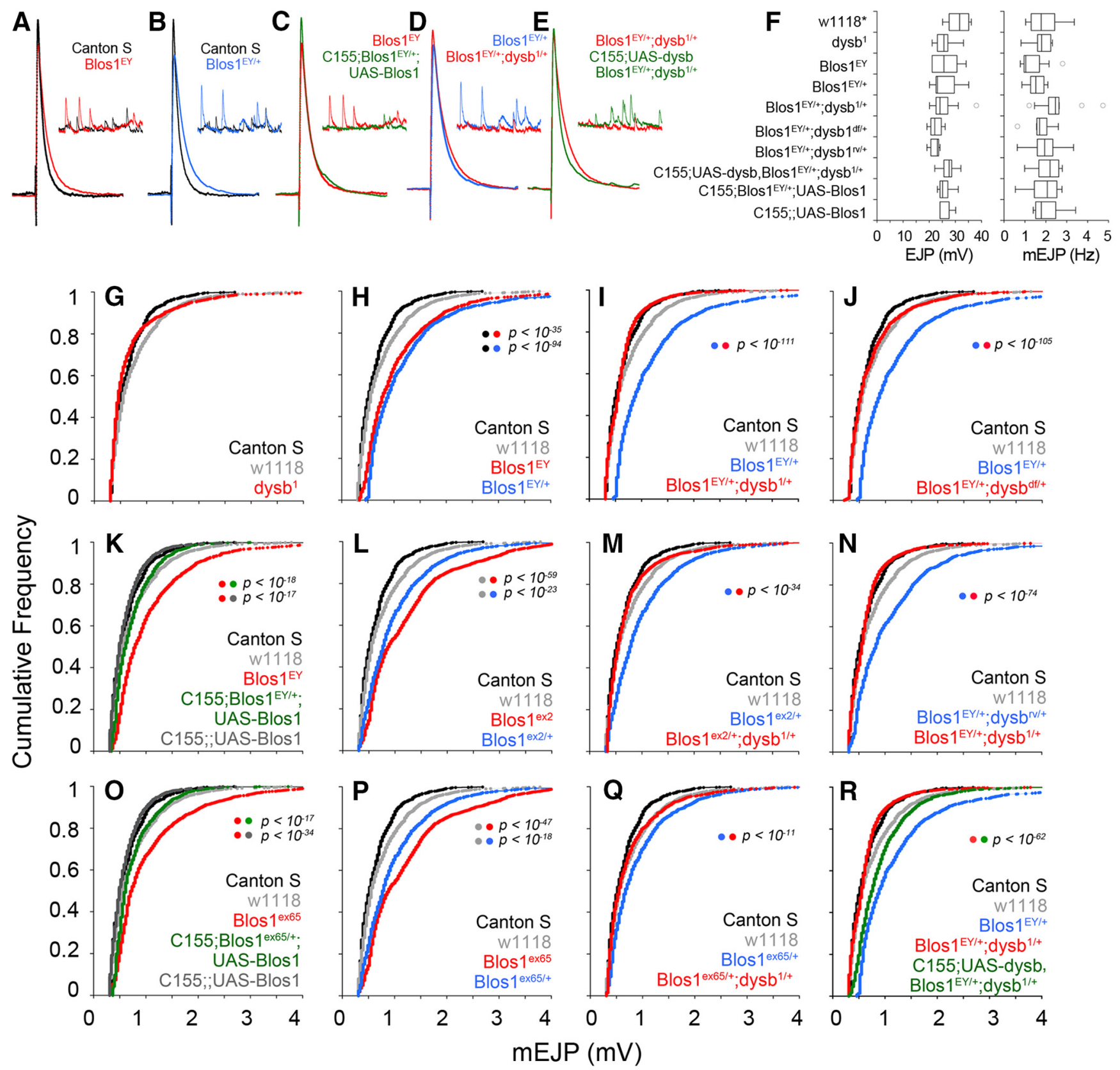

Figure 2. BLOC-1 presynaptically regulates spontaneous neurotransmission at the Drosophila NMJ. $\boldsymbol{A}-\boldsymbol{E}$, Representative EJP and mEJP traces showing Blos 1 -null $\left(\boldsymbol{A}\right.$, red, Blos $\left.{ }^{\mathrm{EY}}\right)$ and Blos1 heterozygote $\left(\boldsymbol{B}\right.$, blue, Blos $1^{\mathrm{EY} /+}$ ) increase $\mathrm{mEJP}$ but not EJP amplitude compared with control (Canton $\mathrm{S}$, black). Presynaptic expression of UAS-Blos1 in a single-copy Blos 1 loss ( $\boldsymbol{C}$, green) or single-copy loss of $B l o s 1$ in trans with the dysb ${ }^{7}$ mutation $\left(\boldsymbol{D}\right.$, red) rescues mEJP amplitude compared withBlos 1 heterozygote $\left(\boldsymbol{C}\right.$ and $\boldsymbol{D}$, blue). Presynaptic expression of dysb in $B$ los $1^{E Y} ;$; dysb $^{7}$ transheterozygote $(\boldsymbol{E}$, green) increases mEJP amplitude compared with the transheterozygote ( $\boldsymbol{E}$, red). No changes in EJP amplitude or mEJP frequency were observed in any of the genotypes. Asterisk denotes that there are no differences between w1118 and Canton S control strains $(\boldsymbol{F}) . \mathbf{G}-\boldsymbol{R}$, Event size plotted against frequency of event for BLOC- 1 loss-of-function allelic combinations. Shift in the curve to the right indicates larger events in that genotype. All comparisons in $\boldsymbol{F}$ were performed with one-way ANOVA followed by Bonferroni's multiple-comparison test. Comparisons were performed by Kolmogorov-Smirnov test. $\boldsymbol{F}-\boldsymbol{R}$, Data were obtained from 7 to 11 animals per genotype. $\mathbf{G}-\boldsymbol{R}$, Plots graph between 992 and 2880 randomly selected mEJP events.

\section{Normal synaptic growth and morphology require BLOC-1 function}

Spontaneous neurotransmission regulates synapse function and morphology, and is required in Drosophila for synaptic structural maturation (Sutton et al., 2004; Choi et al., 2014). For example, gene mutations associated with neurodevelopmental disorders, such as in dFMRP, affect the morphology of Drosophila synapses while displaying spontaneous release phenotypes reminiscent of the Blos1-null phenotype (Reeve et al., 2005; Gatto and Broadie, 2008; Zhao et al., 2013). Therefore, we explored the morphology of the neuromuscular junction in BLOC-1 loss-of-function allele combinations. We sought to test whether synapse morphology phenotypes followed the dominant inheritance defined by the spontaneous release. We performed anti-HRP immunohistochemistry of larval muscle 6/7 synapses to quantify the number of boutons per unit muscle area (Fig. 4). We determined that Blos1null alleles have significantly increased number of boutons per muscle at the 6/7 synapse (Fig. $4 J$, compare $A$ with $B, C$ ). This increase in bouton number occurred without changes in muscle size across genotypes (Fig. $4 K$ ). The increased number of boutons was a dominant phenotype as it was also observed in heterozygous Blos1 mutants (Fig. $4 J$, compare $A$ with $D, E$ ), a 
A

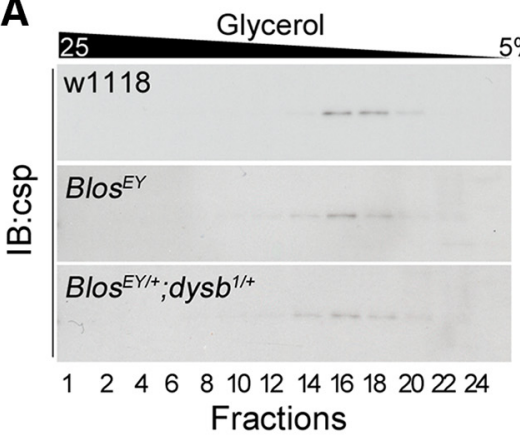

B

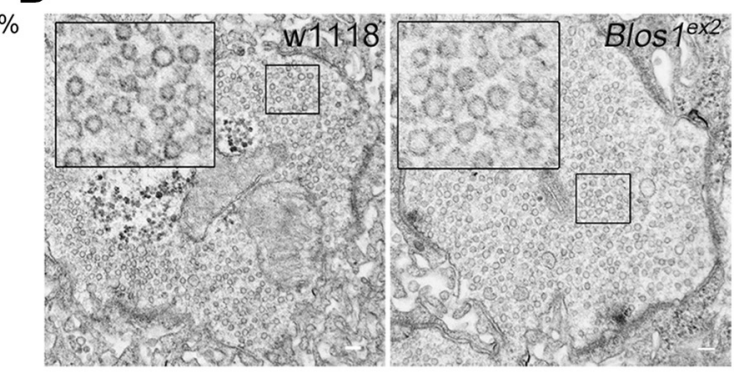

C
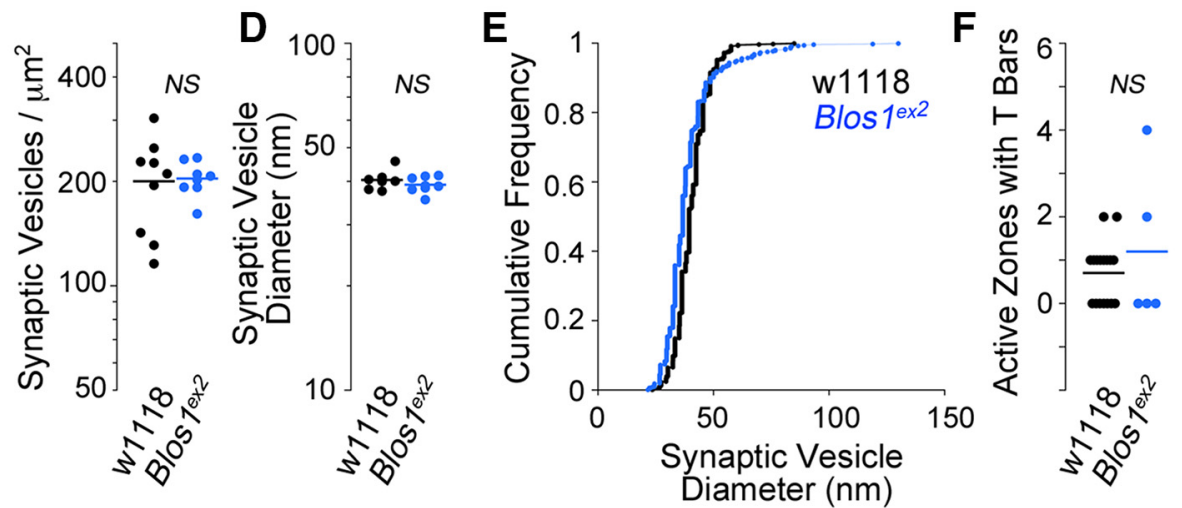

Figure 3. Blos1-null alleles possess normal-sized synaptic vesicles and presynapse ultrastructure. $\boldsymbol{A}$, Adult head homogenates were differentially centrifuged and high-speed supernatants resolved by glycerol velocity sedimentation. Synaptic vesicles in fractions were detected by csp immunoblotting (IB). Csp-positive vesicles peaked at the same fractions regardless of the BLOC-1 genotype. $\boldsymbol{B}$, Representative transmission electron micrographs of larval wild-type (W1118) and Blos1-null (Blos ${ }^{\text {ex2 }}$ ) NMJs. Inserts correspond to threefold magnification of areas boxed. $\boldsymbol{C}, \boldsymbol{D}, \boldsymbol{F}$, Dot plots of synaptic vesicle density, diameter, and the number of T-bars per presynapse, respectively. $\boldsymbol{E}$, frequency plot of synaptic vesicle diameters. No differences were detected among genotypes. All comparisons were made with Wilcoxon-Mann-Whitney test. NS indicates nonsignificant $p$ values. Dot plots depict number of animals analyzed. Black represents wild-type and blue symbols Blos1-null animals, respectively.

genotype-to-phenotype correlation matching the changes in mEJP amplitude and quantal content. Importantly, when a single-copy loss of Blos1-null alleles was expressed in trans with either $d y s b^{1}$ or the $d y s b$ deficiency, the bouton count phenotype was suppressed to resemble wild-type numbers (Fig. 4J, compare $D, E$ with $F, G)$. The specificity of the suppression achieved with the $d y s b^{1}$ allele was tested by expressing Blos 1 mutants in trans with the $d y s b^{1}$ revertant $\left(d y s b^{r v}\right)$, a genotype that phenocopied the Blos1 heterozygotic animals (Fig. 4J, compare F, G and $H, I$ ). These results demonstrate that there is a one-to-one correspondence between genotypes and the bouton morphology and spontaneous release phenotypes at the NMJ. In both instances Blos 1 loss-of-function alleles dominantly affect the phenotypes, which are suppressible by loss-of-function $d y s b$ allele in trans. These results indicate that similar BLOC-1-dependent genetic and molecular mechanisms control spontaneous release and synapse morphology.

\section{Dysbindin and Blos1 are necessary for the function of synaptic vesicle pools}

BLOC-1 loss-of-function allelic combinations have a one-to-one correspondence between genotypes and the bouton morphology and spontaneous release phenotypes. Thus we asked whether this genotype-to-phenotype congruency was observed across multiple synaptic organization levels. We hypothesized that increasingly complex synaptic functions would be similarly sensitive to reductions in the genetic dosage of neuronal BLOC-1 subunits if a common BLOC-1-dependent molecular mechanism controls these synaptic functions. In contrast, if synaptic processes were to respond divergently to the same genetic dosage imbalances, it would indicate that different BLOC-1-dependent molecular mechanisms are required for diverse synapse functions. To differentiate between these hypotheses, we assessed the effect of BLOC-1 genetic dosage on the mobilization of synaptic vesicle pools in response to either a philanthotoxin or high-frequency stimulation challenge (Delgado et al., 2000; Dickman and Davis, 2009; Frank et al., 2013). We focused on the Blos $1^{E Y}$; dysb transheterozygote, as the ability for the $d y s b$ mutations to preclude the dominant effects of Blos1 on mEJP amplitude suggests that synaptic mechanisms require precise BLOC-1 subunit stoichiometry rather than an additive reduction of BLOC-1 complex function.

We first tested the effects of BLOC-1 loss-of-function alleles on philanthotoxin-induced presynaptic homeostatic compensation at the NMJ. In response to an acute, 10 min incubation with philanthotoxin, which irreversibly blocks non-NMDA glutamate receptors, wild-type animals exhibit robust homeostatic compensation to this postsynaptic block, as observed through a reduction in mEJP amplitude while maintaining the amplitude of their EJP (Fig. 5A-A1, compare black and blue traces; Dickman and Davis, 2009; Dickman et al., 2012; Davis, 2013; Frank et al., 2013; Frank, 2014). This synaptic compensation occurs by doubling their quantal content of neurotransmitter release over baseline (Fig. $5 H$ ). However, $d y s b^{1}$ mutants failed to display such presynaptic homeostatic compensation in response to this toxin, as reflected by the unchanged quantal content after toxin incubation (Fig. $5 B, H$, compare black and blue traces). Importantly, single-copy loss of dysbindin does not block synaptic homeostasis (data not shown). Unlike what we observed with the mEJP and branching dominant phenotypes, Blos1-null (Fig. 5C,H) and 

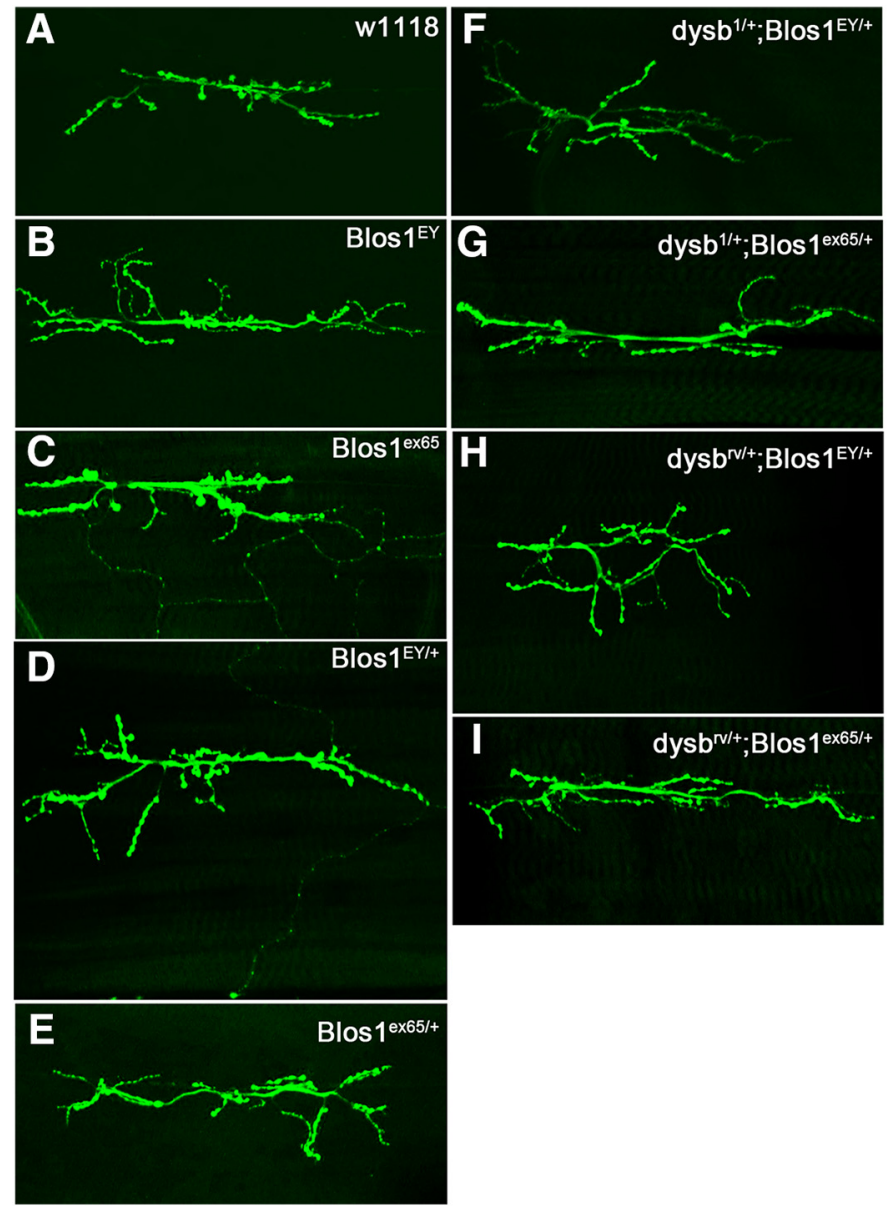
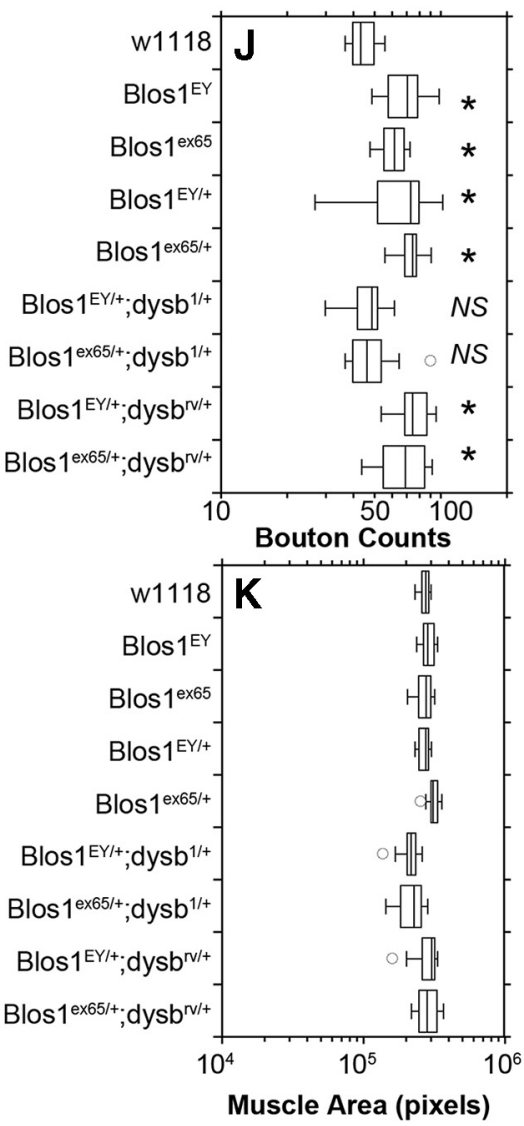

Muscle Area (pixels)

Figure 4. Normal synaptic morphology requires BLOC-1 function. $A-I$, Representative images of HRP immunofluorescence at the $6 / 7$ synapse in Drosophila for indicated genotypes. $J$, Significant increases in the number of synaptic boutons in BLOS1-null animals (Blos $1^{\mathrm{EY}}$, Blos $1^{\mathrm{ex} 65}$ ) and animals carrying single-copy loss of BLOS1 (Blos ${ }^{\mathrm{EY} /+}$, Blos $1^{\mathrm{ex} 65 /+}$, Blos ${ }^{\mathrm{EY} / \mathrm{rv}}$, and Blos ${ }^{\mathrm{ex} 65 / \mathrm{rv}}$ ), but no significant changes in synaptic bouton numbers in Blos ${ }^{\mathrm{EY} /+} ;$ dysb $^{1 /+}$ or Blos ${ }^{\mathrm{ex} 65 /+} ;$ dysb ${ }^{1 /+}$ transheterozygotes. $\boldsymbol{K}$, Muscle area across all genotypes was unaffected. All comparisons were performed with one-way ANOVA followed by Dunnett's multiple-comparison test. Data were obtained from 10 to 14 animals per genotype. *p between 0.0019 and 0.045 and NS indicates nonsignificant $p$ values.

heterozygous animals (Fig. 5D,H) have no defect in synaptic compensation. However, transheterozygotic $B l o s 1^{E Y} ; d y s b^{1}$ mutants blocked synaptic homeostasis to the same extent as $d y s b^{1}$ homozygotic mutants (Fig. $5 A, H$, compare $B, E$ ). These results demonstrate that the BLOC-1 complex is necessary for homeostatic synaptic plasticity, yet the BLOC-1-dependent molecular mechanisms that synaptic homeostasis relies on differ from those required by spontaneous release and synapse morphology. This incongruence in inheritance supports the hypothesis that synaptic mechanisms are differentially sensitive to BLOC-1 gene-dosage imbalances, which do not follow a simple recessive reduction of BLOC-1 complex function.

Increased quantal content during presynaptic homeostatic compensation requires a calcium-dependent increase in size of the readily releasable pool. Thus, we hypothesized that BLOC-1 loss-of-function allele combinations could alter the mobilization of synaptic vesicle pools following the genotype-to-phenotype pattern observed in homeostatic plasticity. To test this hypothesis, we measured the size of the total vesicle pool and the recycling pool in different BLOC-1 mutants. To do this, NMJ responses were recorded under different stimulation frequencies in the presence of the vATPase inhibitor bafilomycin Al. This inhibitor prevents reloading of neurotransmitter into synaptic vesicles after exocytosis. Low-frequency stimulation (3 Hz; Fig. $6 A-C)$, engages the recycling pool of vesicles to maintain neurotransmission; however, intense, high-frequency stimulation $(10 \mathrm{~Hz}$; Fig. $6 D, E)$ mobilizes the reserve pool of vesicles to support neurotransmission (Delgado et al., 2000; Kim et al., 2009). None of the loss-of-function allele combinations affected the rate of vesicle depletion at low-frequency stimulation (Fig. $6 A-C$ ), indicating that BLOC-1 is not required for the mobilization or engagement of the recycling pool. However, we found that Blos 1 homozygous mutants (Fig. $6 E$ ) but not $d y s b^{1}$ mutants (Fig. $6 D$ ) had a significantly enhanced depletion rate of the total vesicle pool compared with wild-type animals and Blos1 single-copy loss. The divergent effects of the Blos 1 and $d y s b^{1}$ homozygous mutants on the mobilization of the total vesicle pool did not reflect BLOC-1 independent functions of these alleles as evidenced by transheterozygotic $B l o s 1^{E Y} ; d y s b^{l}$ mutants, which phenocopied the Blos 1 homozygous animals when stimulated at 10 $\mathrm{Hz}$ (Fig. $6 F$ ). The accelerated rate of depletion of the total vesicle pool paired with a lack of effect on the recycling vesicle pool indicates a selective perturbation to the reserve pool of vesicles in these animals. We conclude that the reserve pool necessitates the BLOC-1 complex, but this BLOC-1 requirement molecularly differs from the BLOC-1 requirement for synaptic homeostatic plasticity. 

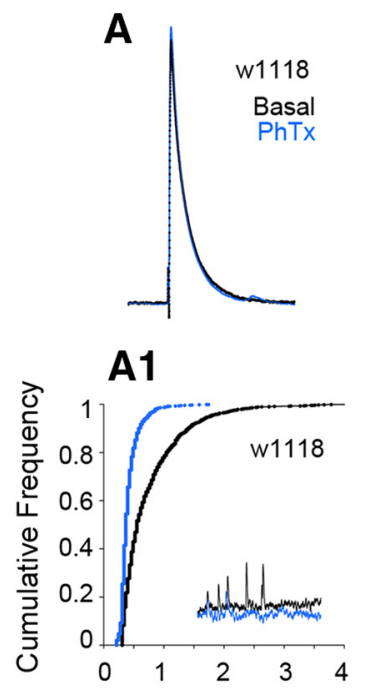

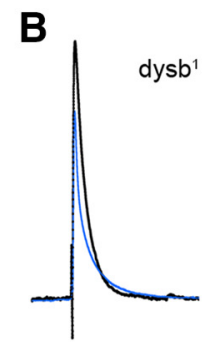

B1

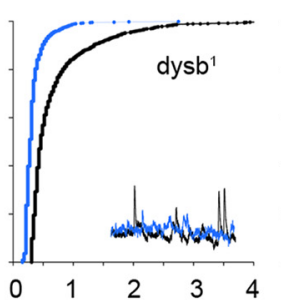

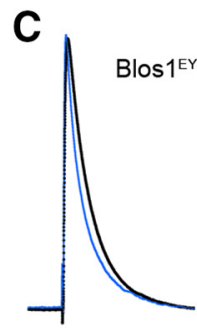

C1

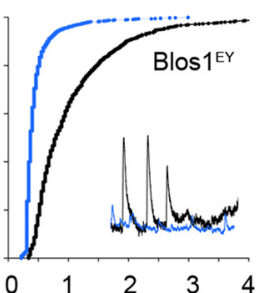

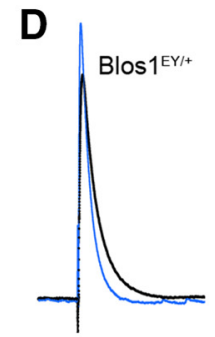

D1

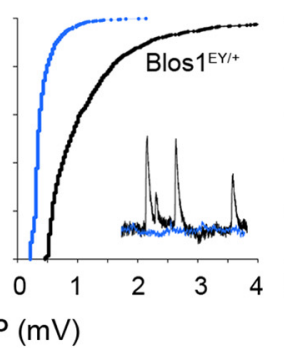

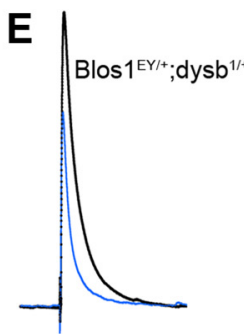

E1

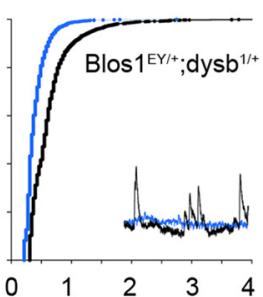

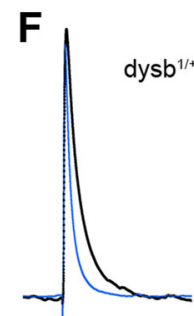

F1

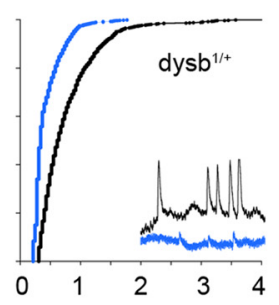

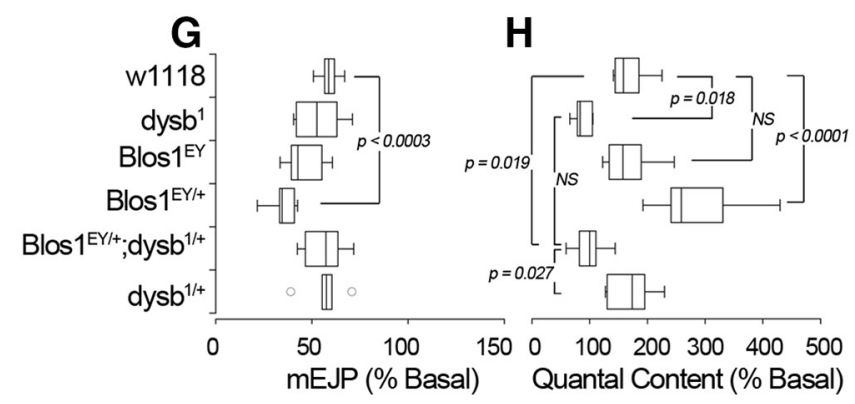

Figure 5. BLOC-1 gene dosage regulates synaptic homeostasis. $\boldsymbol{A}-\boldsymbol{F}$, Representative EJP traces. Black indicates baseline stimulated response; blue indicates response following acute 10 min incubation with $4 \mu \mathrm{m}$ PhTx for each genotype. A1-F1, Reduced mEJP amplitudes following PhTx incubation (blue) compared with baseline (black). Representative mEJP traces shown in inset. G, Reduction in $\mathrm{mEJP}$ amplitude following toxin incubation. $\boldsymbol{H}$, w1118 control, Blos $1^{\mathrm{EY}}$, and Blos $1{ }^{\mathrm{EY} /+}$ animals display robust homeostatic increase in quantal content following toxin incubation, while dysb $^{1}$ and Blos1 ${ }^{\mathrm{EY} /+} ;$;ysb $^{1 /+}$ animals did not. $\boldsymbol{A 1 - E 1 , ~ P l o t s ~ g r a p h ~ b e t w e e n ~} 909$ and 2888 randomly selected mEJP events. All comparisons in $\boldsymbol{G}$ and $\boldsymbol{H}$ were performed with one-way AN0VA followed by Bonferroni's multiple comparison test. Data were obtained from 6 to 11 animals per genotype.

\section{Dysbindin and Blos1 are required for olfactory short-term habituation in Drosophila}

The divergent effects of BLOC-1 subunit gene-dosage reductions among four NMJ synapse phenotypes prompted us to ask how would a learning behavior respond to BLOC-1 subunit genedosage reductions? To address this question, we assessed BLOC-1 mutants in a short-term olfactory habituation assay. Short-term olfactory habituation in adults involves a retrograde signal and mobilization of the reserve pool of vesicles to potentiate GABAergic neurotransmission in the local interneurons (LNs) of the olfactory circuit in Drosophila (Das et al., 2011; Sadanandappa et al., 2013; Twick et al., 2014). Thus, we predicted that this complex learning behavior in adult flies would be affected by BLOC-1 mutations following a genotype-to-phenotype pattern similar to the reserve pool phenotypes (Fig. 6). We explored genotype-tophenotype relationships across different combinations of BLOC-1 loss-of-function alleles (Fig. 7). BLOC-1 mutant flies are healthy and viable, with no defects in locomotion, and can therefore be tested in behavioral assays (data not shown). We trained wild-type and mutant animals with a 30 min aversive odor exposure (5\% ethyl butyrate) to determine odorant-specific reductions in avoidance to a second odor exposure.

Wild-type flies exhibit olfactory habituation as determined by a reduced avoidance response by prior exposure to ethyl butyrate (Fig. 7A, CS, compare pre- and post-test in blue). In contrast, animals homozygous for the $d y s b^{1}$ mutation showed no reduc- tion in avoidance behavior, indicating a deficit in short-term olfactory habituation (Fig. 7A). While the hypomorph $d y s b^{1}$ animals are viable and healthy, the BSC $416 d y s b$ deficiency flies are not. Therefore, to test if the habituation phenotype was $d y s b$ allele specific, we expressed the $d y s b^{1}$ mutation in trans with the $d y s b^{D f}$. Single-copy loss of $d y s b$, either by the $d y s b^{1}$ or the $d y s b^{D f}$ mutation, did not affect habituation (Fig. $7 A$ ). However, short-term olfactory habituation was impaired in $d y s b^{l}$ animals in trans with the dysbindin deficiency (BSC 416; Fig. 7A) confirming that loss of dysbindin inhibits short-term olfactory habituation.

Short-term olfactory habituation requires plasticity in the GABAergic local interneurons and antennal lobe projection neurons, which form a circuit that relays information from olfactory sensory neurons to higher centers, the mushroom bodies and the lateral protocerebrum (Das et al., 2011; Sadanandappa et al., 2013; Twick et al., 2014). We determined the requirement for Dysbindin within these neuronal subtypes by conditionally knocking down dysbindin in a cell type-specific manner. We used $d y s b$ RNAi selectively expressed in the lateral interneurons and antennal lobe projection neurons with the LN1 and GH146-Gal4 drivers, respectively (Das et al., 2011; Sadanandappa et al., 2013). Dysbindin requirement in both cell types for short-term olfactory habituation demonstrate that Dysbindin is necessary for olfactory memory formation (Fig. $7 B$ ). Moreover, the Dysbindin cell-specific requirement is temporally limited to the adult olfactory circuit as determined by experiments that restricted Dysbin- 
A

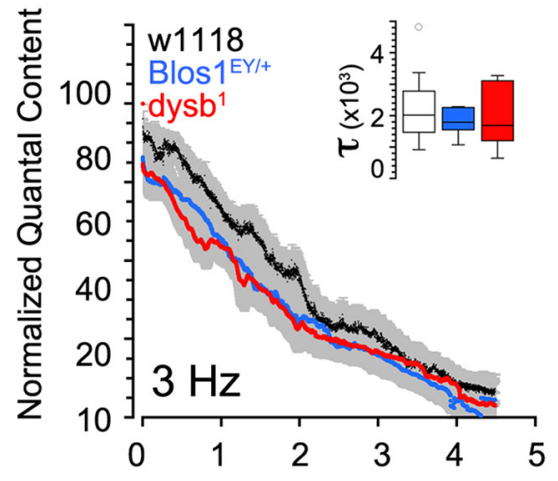

B

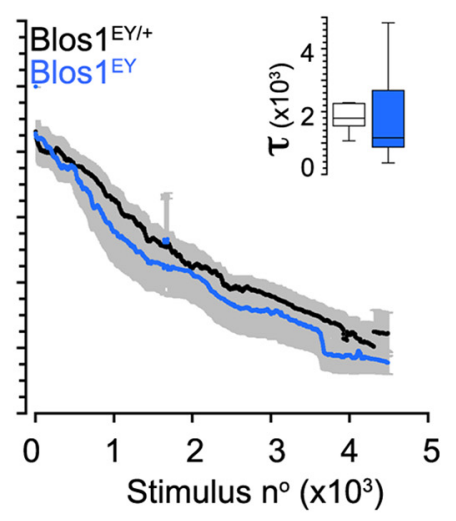

C

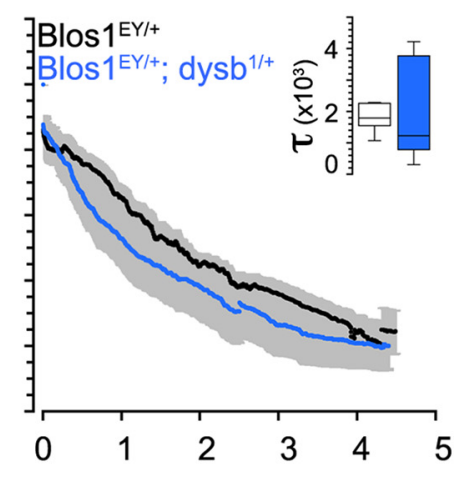

$E$

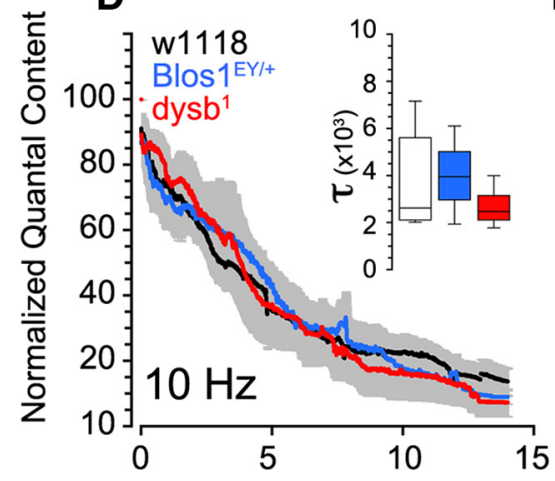

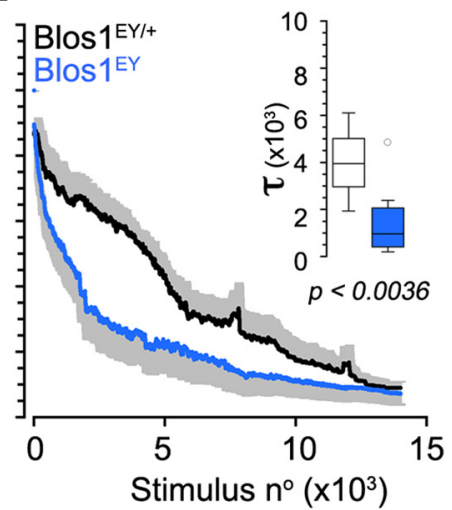

$\mathbf{F}$

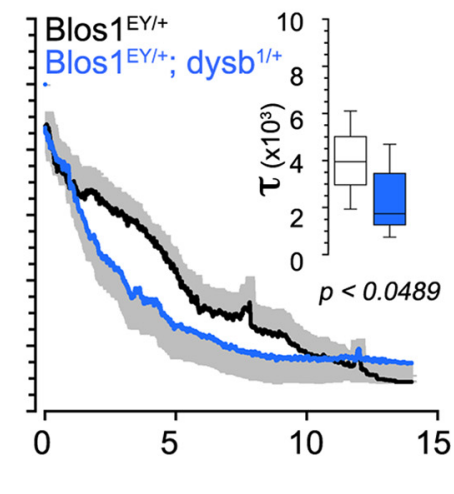

Figure 6. BLOC-1 gene dosage regulates synaptic vesicle pool properties. Animals were stimulated at low frequency $(3 \mathrm{~Hz} ; \boldsymbol{A}-\boldsymbol{C})$ and high frequency $(10 \mathrm{~Hz} ; \mathbf{D}-\boldsymbol{F})$ in the presence of $1 \mu \mathrm{M}$ bafilomycin A1. Inset shows stimulation to $50 \%$ depletion compared with response at stimulation 0 . No changes in rate of vesicle pool depletion were observed across genotypes at low frequency $(\boldsymbol{A}-\boldsymbol{C})$. At high frequency, no changes were observed in vesicle depletion rate in dysb ${ }^{1}\left(\boldsymbol{D}\right.$, red) or Blos $1^{\mathrm{EY} /+}(\boldsymbol{D}$, blue $)$ compared with control $\left(\boldsymbol{D}, \mathrm{w}_{1118}\right.$, black). Blos $1^{\mathrm{EY}}(\boldsymbol{E}$, blue $)$ and Blos $1^{\mathrm{EY} /+}$; dysh $^{1 /+}$ transheterozygote $\left(\boldsymbol{F}\right.$, blue) both displayed significantly faster vesicle depletion compared with the Blos $1^{\mathrm{EY} /+}(\boldsymbol{E}, \boldsymbol{F}$, black). All comparisons in $\boldsymbol{F}$ and $\boldsymbol{G}$ were performed with one-way ANOVA followed by Fisher's multiple comparison. Data were obtained from 6 to 9 animals per genotype.

din knockdown to the adult circuit using the transcriptional repressor tub-Gal80 ${ }^{\text {ts }}$ (Fig. $7 \mathrm{C}, 18^{\circ} \mathrm{C}$ ). Repression of Gal $80^{\text {ts }}$ at the nonpermissive temperature led to the expression of dysbindin-RNAi and impaired olfactory habituation phenotype (Fig. $7 \mathrm{C}, 29^{\circ} \mathrm{C}$ ), whereas at the permissive temperature of $18^{\circ} \mathrm{C}$, olfactory habituation was normal. These data demonstrate that Dysbindin is acutely necessary in the local interneurons and projections neurons during adult Drosophila olfactory habituation.

We next asked whether the observed defect in short-term habituation was specific to loss of the Dysbindin subunit, or if it could be attributed to the BLOC-1 complex. Homozygous loss of Blos1 prevented olfactory short-term habituation (Fig. 7D). Similar to dysbindin, however, a single-copy loss of Blos1 was insufficient to produce the phenotype. While a single-copy loss of each subunit did not preclude short-term habituation, transheterozygotic expression of these mutations did prevent olfactory shortterm habituation (Fig. 7E). We conclude that BLOC-1 is required for olfactory short-term habituation in Drosophila. These results indicate that the genotype-to-phenotype relationships observed for the reserve vesicle pool differ from those observed in olfactory short-term habituation as illustrated by the $d y s b$ homozygous loss-of-function alleles. These data show that the BLOC-1 complex is required regardless of the synapse organization level analyzed or the central or peripheral character of a synapse. However, these BLOC-1 complex requirements follow different genotype-to-phenotype relationships.
Hierarchical clustering analysis of BLOC-1 genotype and associated phenotype

We used the array of genotypes and phenotypes exploring BLOC-1 synaptic functions to quantitatively determine cosegregation of traits with genotypes. We analyzed genotype-tophenotype pairs using single linkage hierarchical clustering (Fig. 8 ). We assigned a value of 0 to wild-type and 1 to mutant phenotypes, respectively. Clustering revealed that a homozygous Blos 1null genotype (Fig. $8 A, B l o s 1^{-/-}$) is phenotypically closer to a Blos1 heterozygote (Fig. $8 A, B l o s 1^{-/+}$) than to homozygous $d y s b$ loss-of-function genotype (Fig. $8 A, d y s b^{-/-}$). In contrast, the phenotypes observed in homozygous $d y s b$ loss-of-function-null flies (Fig. 8A, $d y s b^{-/-}$) cosegregated better with a $d y s b$, Blos 1 transheterozygotes (Fig. 8A, Blos1/dysb). Similarly, mEJP amplitude and branching dominant traits were clustered together and away from the presynaptic homeostasis, reserve pool, and habituation phenotypes. Phenotype and genotype clustering were different from randomized phenotype-genotype pairs (Fig. 8B). This analysis shows that an array of six genotypes and five traits identify as a minimum two nonoverlapping phenotypic clusters within a collection of BLOC-1 loss-of-function mutations. Our findings demonstrate that alleles reducing the function of the BLOC-1 protein complex at the synapse are modified by a second complex subunit-encoding locus. However, these genetic interactions depart from Mendelian inheritance even though alleles affect the same restricted molecular network. 
A

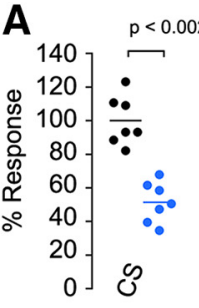

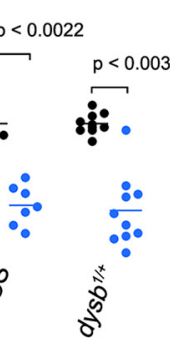
$p<0.0002$

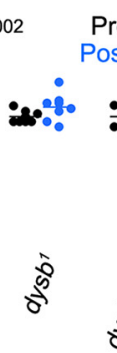

B
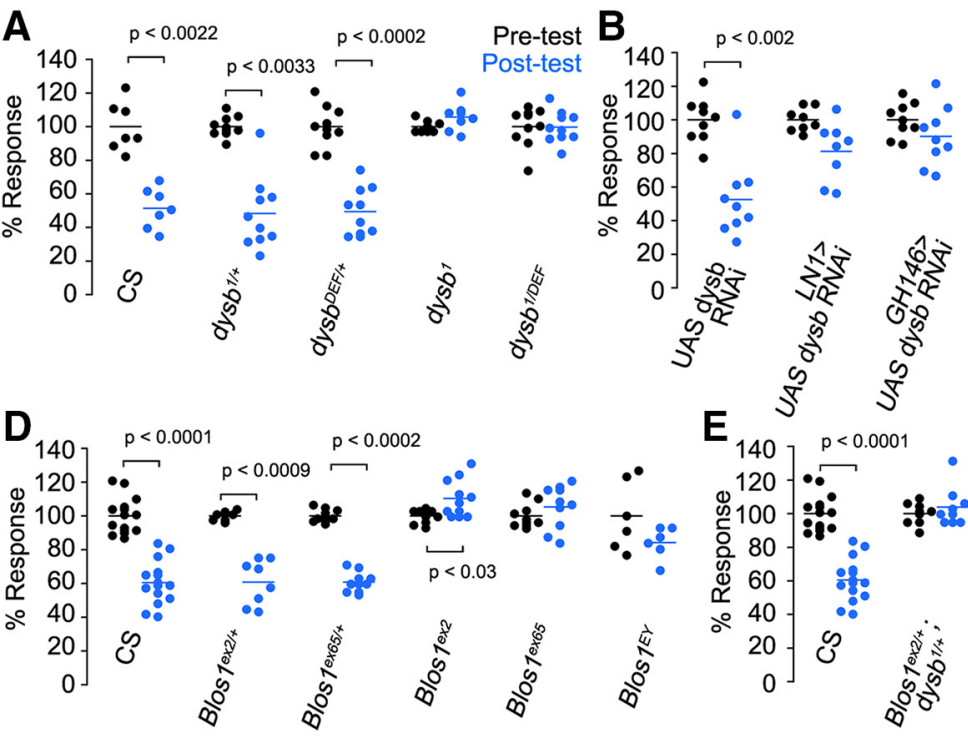

E $_{140} S_{p<0.0001}^{5}$

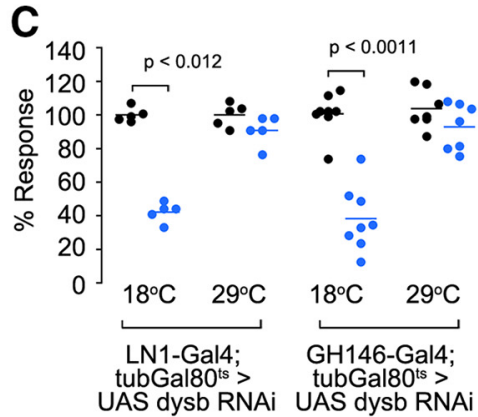

Figure 7. BLOC-1 is required at LNs and projection neurons for short-term olfactory habituation in Drosophila. Following aversive odor exposure, control (Canton S, CS) or single-copy loss-of-function (dysb ${ }^{1 /+}$, dysb ${ }^{\mathrm{DF} /+}$ ) animals show significant avoidance behavior, represented as \% Response, compared with pre-exposure response (A, compare blue dots to black). dysb mutants (dysb ${ }^{1}$ and dysb ${ }^{1 / D f}$ ) show no learned avoidance following aversive odor exposure. $\boldsymbol{B}$, Specific expression of dysbindin RNAi in either the LNs (LN1 driver) or projection neurons (GH146 driver) is sufficient to prevent normal postexposure avoidance response. $C$, Inhibition of dysbindin RNAi expression in the LNs or the projection neurons using the temperature-sensitive repressor tubGal $80^{\text {ts }}$ at the permissive temperature $\left(18^{\circ} \mathrm{C}\right.$ allowed for normal olfactory habituation. Repression of tubGal $80^{\text {ts }}$ at the nonpermissive temperature $\left(29^{\circ} \mathrm{C}\right)$ led to impaired odorant-avoidance response. $\boldsymbol{D}$, Blos 1 homozygous mutations but no single-copy loss prevent learned odorant-avoidance behavior. $\boldsymbol{E}$, Blos 1 mutations expressed in trans with dysb ${ }^{1}$ prevent learned odorant-avoidance response. Dot plots represent independent experiment per genotype. Comparisons were made with Wilcoxon-Mann-Whitney test.

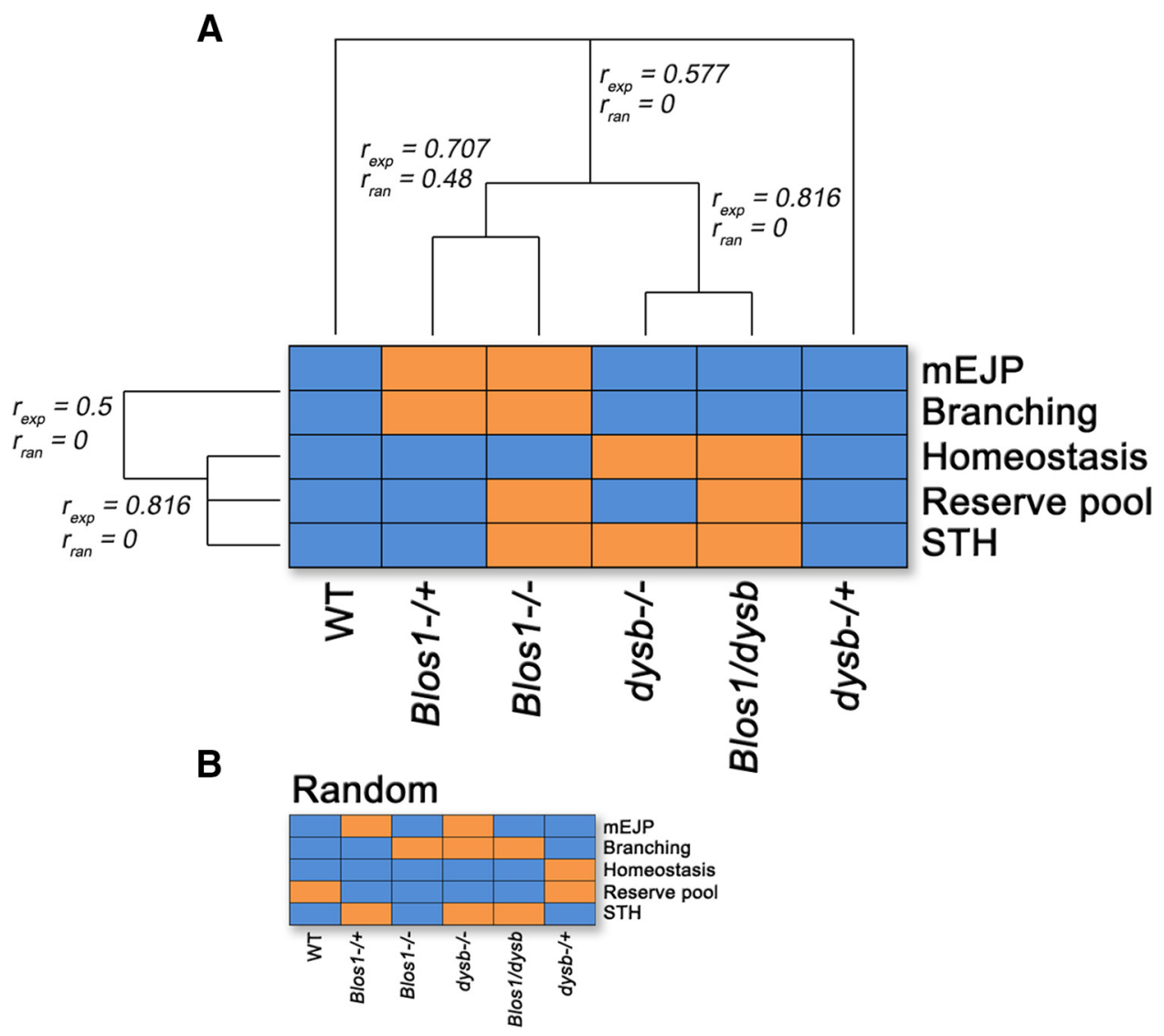

Figure 8. Hierarchical clustering analysis of BLOC-1 genotype and their associated phenotypes. Genotype-to-phenotype pairs were analyzed by single linkage hierarchical clustering. Phenotypes are assigned a value of 0 to wild-type (blue) and 1 to mutant phenotypes (orange), respectively. $A$, Depicts experimentally generated genotype-to-phenotype pairs. $\boldsymbol{B}$, Represents randomly assigned genotype-to-phenotype pairs. Hierarchical clustering analysis was performed for $\boldsymbol{A}$ and $\boldsymbol{B}$ and cluster $r$ values are presented in $\boldsymbol{A}$ : $r$ experimental $\left(r_{\exp }\right)$ and $r$ random $\left(r_{\text {ran }}\right)$. All experimentally defined cluster $r$ correlations are different from those predicted from random genotype-to-phenotype pairs. See text for details. 


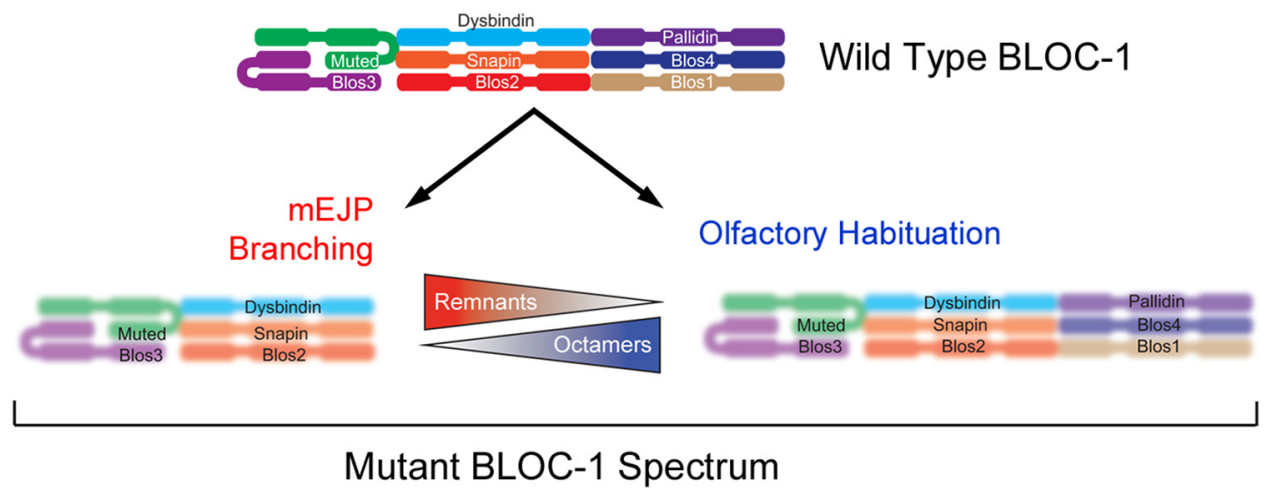

Figure 9. How do BLOC-1 mutations produce divergent synaptic phenotypes? Model depicts the wild-type BLOC-1 complex and two outcomes of gene loss-of-function alleles on the levels and putative architecture of BLOC-1 and remnants (blurred structures). Mutations induce a downregulation of the whole BLOC-1 octamer (bottom left) and/or generate low levels of BLOC- 1 remnants (bottom right). The extent of these two molecular outcomes would be dependent of the mutations affecting BLOC-1 subunit genes. Phenotypes emerge either because of downregulation of the BLOC-1 octamer or the appearance of remnants. See discussion for details.

\section{Discussion}

Here, we examined the impact of combined loss-of-function mutations affecting the BLOC-1 complex on synaptic neurotransmission in Drosophila. BLOC-1 is a closely associating octameric protein complex whose interaction network we defined in the fly through the schizophrenia susceptibility factor and BLOC-1 subunit Dysbindin (Fig. 1; Cheli et al., 2010; Guruharsha et al., 2011). We found that homozygous loss-of-function alleles of $d y s b$, Blos 1, or compound heterozygotes of these alleles impaired diverse presynaptic mechanisms. These identified deficits affect mechanisms of increasing complexity, from abnormal spontaneous neurotransmitter release and synapse morphology at the neuromuscular junction to olfactory habituation. This multiparameter assessment indicated that phenotypes were differentially sensitive to genetic reductions of BLOC-1 function in a way that departs from the predicted recessive inheritance of dysbindin loss of function. On one extreme, spontaneous neurotransmission and synapse morphology at the NMJ follow a dominant inheritance in response to Blos 1 loss of function (Figs. 2-4). This phenotype is rescued by a second loss-of-function allele in $d y s b$. This is particularly striking when we consider that the polypeptides encoded by these genes form a complex, as we demonstrated in Drosophila neurons (Fig. 1). In contrast, short-term olfactory habituation behaves as a recessive character (Fig. 7). We draw two conclusions from these findings that we would like to focus on. First, gene-dosage reductions in two or more genetic loci encoding BLOC-1 polypeptides, which belong to the same protein interaction network, do not confer strictly additive functional consequences. Second, genotype-to-phenotype correlations observed in a BLOC-1 trait following a gene pair analysis better predict, although not precisely, how other traits may respond. These findings provide a perspective to the complexity and predictability of synaptic phenotypes derived from copy number variation associated to human neurodevelopmental disorders (Stefansson et al., 2009, 2014 Bassett et al., 2010; Malhotra and Sebat, 2012; Rapoport et al., 2012; Moreno-De-Luca et al., 2013; Ahn et al., 2014).

Dominant and recessive fly traits associated with mutations affecting BLOC-1 complexes support the dosage balance hypothesis, which predicts that mutations affecting genes encoding different subunits of a protein complex may confer distinct phenotypes and inheritance mechanisms (Veitia et al., 2008; Birchler and Veitia, 2012). The ultimate result is a range of resultant subcomplex remnants spanning from total complex deple- tion to combinations of residual subunits, referred to here as remnants. These remnants have been described in mice carrying mutations in genes encoding BLOC-1 complex subunits, including dysbindin. However, no phenotype has been assigned to these remnants to date (Huang et al., 1999; Zhang et al., 2002; Ciciotte et al., 2003; Li et al., 2003; Gwynn et al., 2004; Starcevic and Dell'Angelica, 2004; Yang et al., 2012). We postulate that olfactory habituation, a BLOC- 1 recessive phenotype, is at one end of this spectrum and requires fully assembled octameric BLOC-1, which would be disrupted by any BLOC-1 subunit mutation. Further, olfactory habituation mechanisms would be unaffected by BLOC-1 remnants (Fig. 9). In contrast, traits that depart from a recessive inheritance pattern and display diverse responses to BLOC-1 subunit mutations may be caused by at least three nonmutually exclusive mechanisms related to the dosage balance hypothesis. First, mutations in different BLOC-1 subunits may result in similar reductions of BLOC-1 content and activity. However, traits may be differentially sensitive to total BLOC-1 cellular content. Second, divergent phenotypes in response to gene-dosage reductions may reflect different functions engaged by distinct BLOC-1 subunits, performed by either monomeric subunits or monomers as part of other protein complexes. Finally, loss-of-function mutations affecting BLOC-1 subunits may lead to gain-of-function remnants (Fig. 9). Thus, some phenotypes may emerge from these BLOC-1 complex remnants left over after uneven protein downregulation of the octamer. The remnant hypothesis best explains the mEJP amplitude phenotypes, which lie at the other end of the spectrum from olfactory habituation. If increased mEJP amplitude is caused by Blos $1 \mathrm{mu}-$ tations leaving behind "deleterious," Dysbindin-containing subcomplex remnants, then reducing Dysbindin levels by $d y s b$ mutations should restore mEJP amplitude to wild-type levels. This prediction is satisfied by our results with multiple Blos 1 and $d y s b$ allele combinations (Fig. 2). Thus, the mEJP amplitude phenotype suggests the existence of a class of neurodevelopmental disease phenotypes that do not simply result from network loss of function but rather from changes in the stoichiometry of network components. It is possible that a loss-of-function allele in $D T N B P 1$ or other gene may increase the risk or be causative of a disease trait when in isolation yet have no consequences when combined with another gene defect affecting the network. We speculate that philanthotoxin-induced homeostasis and reserve pool mobilization are differentially sensitive to BLOC-1 rem- 
nants, and that these phenotypes reside somewhere in the middle of this spectrum.

In this study, we modeled a two-gene synaptic neurodevelopmental defect in the fly in an effort to comprehend how multiple genes influence synaptic functions that may be compromised in schizophrenia. Our strategy is founded on the polygenic character of schizophrenia, illustrated by copy number variations that strongly confer disease risk (Gottesman and Shields, 1967; Mirnics et al., 2000; Purcell et al., 2009, 2014; Faludi and Mirnics, 2011). Here, we focus on the product of a gene associated to schizophrenia susceptibility and a modulator of brain structure and cognition in normal humans, dysbindin (Straub et al., 2002; Van Den Bogaert et al., 2003; Bray et al., 2005; Luciano et al., 2009; Markov et al., 2009, 2010; Mechelli et al., 2010; Cerasa et al., 2011; Mullin et al., 2011; Tognin et al., 2011; Wolf et al., 2011; Ghiani and Dell'Angelica, 2011; Ayalew et al., 2012; Papaleo et al., 2014). Moreover, similar to Drosophila $d y s b$ alleles, cognitive traits associated to alleles of the human $d y s b$ ortholog, DTNBP1, are modified by a second locus in a human dysbindin functional interactome (Papaleo et al., 2014). Finally, mutations in Drosophila genes encoding the BLOC-1 subunits Dysbindin and Blos1 preclude short-term olfactory habituation, as established here (Fig. 7). We draw several parallels between our analyses in the fly and observed deficits in schizophrenia, which make our study of particular relevance. First, Drosophila olfactory habituation is mediated by GABAergic interneurons, which modulate the output of odorant-selective projection neurons to mushroom bodies (Das et al., 2011; Sadanandappa et al., 2013; Twick et al., 2014). We demonstrate the requirement of BLOC-1 function in these interneurons in short-term olfactory habituation. GABAergic interneuron dysfunction is also observed in mice lacking dysbindin (Carlson et al., 2011; Larimore et al., 2014), as well as in both the prefrontal cortex and hippocampus of schizophrenia patients (Benes and Berretta, 2001; Beasley et al., 2002; Hashimoto et al., 2003, 2008; Nakazawa et al., 2012). Second, impaired sensory habituation is a common manifestation in schizophrenia subjects (Geyer and Braff, 1987; Braff et al., 1992; Holt et al., 2005; Williams et al., 2013; Hu et al., 2014). In humans, sensory habituation defects are considered an intermediate, or "endo"phenotype. In complex genetic disorders such as schizophrenia, endophenotypes may serve as useful biological markers, bridging diagnostic phenomenology with cellular and molecular mechanisms of disease (Gottesman and Gould, 2003). As such, our studies are the first example of deconstructing an endophenotype, sensory habituation, into lower complexity synaptic mechanisms in Drosophila. We measured distinct functional properties of synapses that could be substrates of defective sensory habituation. While none of the synaptic functions assessed precisely matched their response to combinations of gene-dosage reductions, sensory habituation clustered with synaptic plasticity mechanisms observed during high-frequency stimulation and philanthotoxin-induced synaptic homeostasis (Fig. 8). Clustering of phenotypes and their underlying mechanisms is most clearly perceived through the study of combined heterozygotic gene defects. These findings demonstrate that mechanistic deconstruction of an endophenotype is better understood through assessments spanning different levels of synaptic organization and complexity, as well as through genetic perturbations of two or more genes encoding network components.

\section{References}

Ahn K, Gotay N, Andersen TM, Anvari AA, Gochman P, Lee Y, Sanders S, Guha S, Darvasi A, Glessner JT, Hakonarson H, Lencz T, State MW,
Shugart YY, Rapoport JL (2014) High rate of disease-related copy number variations in childhood onset schizophrenia. Mol Psychiatry 19:568 572. CrossRef Medline

Ayalew M, Le-Niculescu H, Levey DF, Jain N, Changala B, Patel SD, Winiger E, Breier A, Shekhar A, Amdur R, Koller D, Nurnberger JI, Corvin A, Geyer M, Tsuang MT, Salomon D, Schork NJ, Fanous AH, O'Donovan MC, Niculescu AB (2012) Convergent functional genomics of schizophrenia: from comprehensive understanding to genetic risk prediction. Mol Psychiatry 17:887-905. CrossRef Medline

Bassett AS, Scherer SW, Brzustowicz LM (2010) Copy number variations in schizophrenia: critical review and new perspectives on concepts of genetics and disease. Am J Psychiatry 167:899-914. CrossRef Medline

Beasley CL, Zhang ZJ, Patten I, Reynolds GP (2002) Selective deficits in prefrontal cortical GABAergic neurons in schizophrenia defined by the presence of calcium-binding proteins. Biol Psychiatry 52:708-715. CrossRef Medline

Benes FM, Berretta S (2001) GABAergic interneurons: implications for understanding schizophrenia and bipolar disorder. Neuropsychopharmacology 25:1-27. CrossRef Medline

Birchler JA, Veitia RA (2012) Gene balance hypothesis: connecting issues of dosage sensitivity across biological disciplines. Proc Natl Acad Sci U S A 109:14746-14753. CrossRef Medline

Braff DL, Grillon C, Geyer MA (1992) Gating and habituation of the startle reflex in schizophrenic patients. Arch Gen Psychiatry 49:206-215. CrossRef Medline

Bray NJ, Preece A, Williams NM, Moskvina V, Buckland PR, Owen MJ, O’Donovan MC (2005) Haplotypes at the dystrobrevin binding protein 1 (DTNBP1) gene locus mediate risk for schizophrenia through reduced DTNBP1 expression. Hum Mol Genet 14:1947-1954. CrossRef Medline

Carlson GC, Talbot K, Halene TB, Gandal MJ, Kazi HA, Schlosser L, Phung QH, Gur RE, Arnold SE, Siegel SJ (2011) Dysbindin-1 mutant mice implicate reduced fast-phasic inhibition as a final common disease mechanism in schizophrenia. Proc Natl Acad Sci U S A 108:E962-E970. CrossRef Medline

Cerasa A, Quattrone A, Gioia MC, Tarantino P, Annesi G, Assogna F, Caltagirone C, De Luca V, Spalletta G (2011) Dysbindin C-A-T haplotype is associated with thicker medial orbitofrontal cortex in healthy population. Neuroimage 55:508-513. CrossRef Medline

Cheli VT, Daniels RW, Godoy R, Hoyle DJ, Kandachar V, Starcevic M, Martinez-Agosto JA, Poole S, DiAntonio A, Lloyd VK, Chang HC, Krantz DE, Dell'Angelica EC (2010) Genetic modifiers of abnormal organelle biogenesis in a Drosophila model of BLOC-1 deficiency. Hum Mol Genet 19:861-878. CrossRef Medline

Choi BJ, Imlach WL, Jiao W, Wolfram V, Wu Y, Grbic M, Cela C, Baines RA, Nitabach MN, McCabe BD (2014) Miniature neurotransmission regulates Drosophila synaptic structural maturation. Neuron 82:618-634. CrossRef Medline

Ciciotte SL, Gwynn B, Moriyama K, Huizing M, Gahl WA, Bonifacino JS, Peters LL (2003) Cappuccino, a mouse model of Hermansky-Pudlak syndrome, encodes a novel protein that is part of the pallidin-muted complex (BLOC-1). Blood 101:4402-4407. CrossRef Medline

Das S, Sadanandappa MK, Dervan A, Larkin A, Lee JA, Sudhakaran IP, Priya R, Heidari R, Holohan EE, Pimentel A, Gandhi A, Ito K, Sanyal S, Wang JW, Rodrigues V, Ramaswami M (2011) Plasticity of local GABAergic interneurons drives olfactory habituation. Proc Natl Acad Sci U S A 108: E646-654. CrossRef Medline

Davis GW (2013) Homeostatic signaling and the stabilization of neural function. Neuron 80:718-728. CrossRef Medline

Delgado R, Maureira C, Oliva C, Kidokoro Y, Labarca P (2000) Size of vesicle pools, rates of mobilization, and recycling at neuromuscular synapses of a Drosophila mutant, shibire. Neuron 28:941-953. CrossRef Medline

Dickman DK, Davis GW (2009) The schizophrenia susceptibility gene dysbindin controls synaptic homeostasis. Science 326:1127-1130. CrossRef Medline

Dickman DK, Tong A, Davis GW (2012) Snapin is critical for presynaptic homeostatic plasticity. J Neurosci 32:8716-8724. CrossRef Medline

Eisen MB, Spellman PT, Brown PO, Botstein D (1998) Cluster analysis and display of genome-wide expression patterns. Proc Natl Acad Sci U S A 95:14863-14868. CrossRef Medline

Faludi G, Mirnics K (2011) Synaptic changes in the brain of subjects with schizophrenia. Int J Dev Neurosci 29:305-309. CrossRef Medline

Fatjó-Vilas M, Papiol S, Estrada G, Bombín I, Peralta V, Rosa A, Parellada M, 
Miret S, Martín M, Lázaro L, Campanera S, Muñoz MJ, Lera-Miguel S, Arias B, Navarro ME, Castro-Fornieles J, Cuesta MJ, Arango C, Fañanás L (2011) Dysbindin-1 gene contributes differentially to early- and adultonset forms of functional psychosis. Am J Med Genet B Neuropsychiatr Genet 156B:322-333. CrossRef Medline

Franciscovich AL, Mortimer AD, Freeman AA, Gu J, Sanyal S (2008) Overexpression screen in Drosophila identifies neuronal roles of GSK-3 beta/ shaggy as a regulator of AP-1-dependent developmental plasticity. Genetics 180:2057-2071. CrossRef Medline

Frank CA (2014) Homeostatic plasticity at the Drosophila neuromuscular junction. Neuropharmacology 78:63-74. CrossRef Medline

Frank CA, Wang X, Collins CA, Rodal AA, Yuan Q, Verstreken P, Dickman DK (2013) New approaches for studying synaptic development, function, and plasticity using Drosophila as a model system. J Neurosci 33: 17560-17568. CrossRef Medline

Gatto CL, Broadie K (2008) Temporal requirements of the fragile X mental retardation protein in the regulation of synaptic structure. Development 135:2637-2648. CrossRef Medline

Geyer MA, Braff DL (1987) Startle habituation and sensorimotor gating in schizophrenia and related animal models. Schizophr Bull 13:643-668. CrossRef Medline

Ghiani CA, Dell'Angelica EC (2011) Dysbindin-containing complexes and their proposed functions in brain: from zero to (too) many in a decade. ASN Neuro 3:e00058. CrossRef Medline

Gokhale A, Larimore J, Werner E, So L, Moreno-De-Luca A, Lese-Martin C, Lupashin VV, Smith Y, Faundez V (2012) Quantitative proteomic and genetic analyses of the schizophrenia susceptibility factor dysbindin identify novel roles of the biogenesis of lysosome-related organelles complex 1. J Neurosci 32:3697-3711. CrossRef Medline

Gornick MC, Addington AM, Sporn A, Gogtay N, Greenstein D, Lenane M, Gochman P, Ordonez A, Balkissoon R, Vakkalanka R, Weinberger DR, Rapoport JL, Straub RE (2005) Dysbindin (DTNBP1, 6p22.3) is associated with childhood-onset psychosis and endophenotypes measured by the Premorbid Adjustment Scale (PAS). J Autism Dev Disord 35:831838. CrossRef Medline

Gottesman II, Gould TD (2003) The endophenotype concept in psychiatry: etymology and strategic intentions. Am J Psychiatry 160:636-645. CrossRef Medline

Gottesman II, Shields J (1967) A polygenic theory of schizophrenia. Proc Natl Acad Sci U S A 58:199-205. CrossRef Medline

Greenspan RJ (2009) Selection, gene interaction, and flexible gene networks. Cold Spring Harb Symp Quant Biol 74:131-138. CrossRef Medline

Guruharsha KG, Rual JF, Zhai B, Mintseris J, Vaidya P, Vaidya N, Beekman C, Wong C, Rhee DY, Cenaj O, McKillip E, Shah S, Stapleton M, Wan KH, Yu C, Parsa B, Carlson JW, Chen X, Kapadia B, VijayRaghavan K, et al. (2011) A protein complex network of Drosophila melanogaster. Cell 147: 690-703. CrossRef Medline

Gwynn B, Martina JA, Bonifacino JS, Sviderskaya EV, Lamoreux ML, Bennett DC, Moriyama K, Huizing M, Helip-Wooley A, Gahl WA, Webb LS, Lambert AJ, Peters LL (2004) Reduced pigmentation (rp), a mouse model of Hermansky-Pudlak syndrome, encodes a novel component of the BLOC-1 complex. Blood 104:3181-3189. CrossRef Medline

Hashimoto T, Volk DW, Eggan SM, Mirnics K, Pierri JN, Sun Z, Sampson AR, Lewis DA (2003) Gene expression deficits in a subclass of GABA neurons in the prefrontal cortex of subjects with schizophrenia. J Neurosci 23:6315-6326. Medline

Hashimoto T, Arion D, Unger T, Maldonado-Avilés JG, Morris HM, Volk DW, Mirnics K, Lewis DA (2008) Alterations in GABA-related transcriptome in the dorsolateral prefrontal cortex of subjects with schizophrenia. Mol Psychiatry 13:147-161. CrossRef Medline

Heerssen H, Fetter RD, Davis GW (2008) Clathrin dependence of synapticvesicle formation at the Drosophila neuromuscular junction. Curr Biol 18:401-409. CrossRef Medline

Holt DJ, Weiss AP, Rauch SL, Wright CI, Zalesak M, Goff DC, Ditman T, Welsh RC, Heckers S (2005) Sustained activation of the hippocampus in response to fearful faces in schizophrenia. Biol Psychiatry 57:1011-1019. CrossRef Medline

Hu FK, He S, Fan Z, Lupiáñez J (2014) Beyond the inhibition of return of attention: reduced habituation to threatening faces in schizophrenia. Front Psychiatry 5:7. CrossRef Medline

Huang L, Kuo YM, Gitschier J (1999) The pallid gene encodes a novel, syn- taxin 13-interacting protein involved in platelet storage pool deficiency. Nat Genet 23:329-332. CrossRef Medline

Kendler KS, Greenspan RJ (2006) The nature of genetic influences on behavior: lessons from "simpler" organisms. Am J Psychiatry 163:16831694. CrossRef Medline

Kim SM, Kumar V, Lin YQ, Karunanithi S, Ramaswami M (2009) Fos and Jun potentiate individual release sites and mobilize the reserve synaptic vesicle pool at the Drosophila larval motor synapse. Proc Natl Acad Sci U S A 106:4000-4005. CrossRef Medline

Larimore J, Zlatic SA, Gokhale A, Tornieri K, Singleton KS, Mullin AP, Tang J, Talbot K, Faundez V (2014) Mutations in the BLOC-1 subunits dysbindin and muted generate divergent and dosage-dependent phenotypes. J Biol Chem 289:14291-14300. CrossRef Medline

Li W, Zhang Q, Oiso N, Novak EK, Gautam R, O'Brien EP, Tinsley CL, Blake DJ, Spritz RA, Copeland NG, Jenkins NA, Amato D, Roe BA, Starcevic M, Dell'Angelica EC, Elliott RW, Mishra V, Kingsmore SF, Paylor RE, Swank RT (2003) Hermansky-Pudlak syndrome type 7 (HPS-7) results from mutant dysbindin, a member of the biogenesis of lysosome-related organelles complex 1 (BLOC-1). Nat Genet 35:84-89. CrossRef Medline

Luciano M, Miyajima F, Lind PA, Bates TC, Horan M, Harris SE, Wright MJ, Ollier WE, Hayward C, Pendleton N, Gow AJ, Visscher PM, Starr JM, Deary IJ, Martin NG, Payton A (2009) Variation in the dysbindin gene and normal cognitive function in three independent population samples. Genes Brain Behav 8:218-227. CrossRef Medline

Malhotra D, Sebat J (2012) CNVs: harbingers of a rare variant revolution in psychiatric genetics. Cell 148:1223-1241. CrossRef Medline

Markov V, Krug A, Krach S, Whitney C, Eggermann T, Zerres K, Stöcker T, Shah NJ, Nöthen MM, Treutlein J, Rietschel M, Kircher T (2009) Genetic variation in schizophrenia-risk-gene dysbindin 1 modulates brain activation in anterior cingulate cortex and right temporal gyrus during language production in healthy individuals. Neuroimage 47:2016-2022. CrossRef Medline

Markov V, Krug A, Krach S, Jansen A, Eggermann T, Zerres K, Stöcker T, Shah NJ, Nöthen MM, Treutlein J, Rietschel M, Kircher T (2010) Impact of schizophrenia-risk gene dysbindin 1 on brain activation in bilateral middle frontal gyrus during a working memory task in healthy individuals. Hum Brain Mapp 31:266-275. CrossRef Medline

Mechelli A, Viding E, Kumar A, Pettersson-Yeo W, Fusar-Poli P, Tognin S, O’Donovan MC, McGuire P (2010) Dysbindin modulates brain function during visual processing in children. Neuroimage 49:817-822. CrossRef Medline

Mirnics K, Middleton FA, Marquez A, Lewis DA, Levitt P (2000) Molecular characterization of schizophrenia viewed by microarray analysis of gene expression in prefrontal cortex. Neuron 28:53-67. CrossRef Medline

Moreno-De-Luca A, Myers SM, Challman TD, Moreno-De-Luca D, Evans DW, Ledbetter DH (2013) Developmental brain dysfunction: revival and expansion of old concepts based on new genetic evidence. Lancet Neurol 12:406-414. CrossRef Medline

Mullin AP, Gokhale A, Larimore J, Faundez V (2011) Cell biology of the BLOC-1 complex subunit dysbindin, a schizophrenia susceptibility gene. Mol Neurobiol 44:53-64. CrossRef Medline

Mullin AP, Gokhale A, Moreno-De-Luca A, Sanyal S, Waddington JL, Faundez V (2013) Neurodevelopmental disorders: mechanisms and boundary definitions from genomes, interactomes and proteomes. Trans Psychiatry 3:e329. CrossRef Medline

Nakazawa K, Zsiros V, Jiang Z, Nakao K, Kolata S, Zhang S, Belforte JE (2012) GABAergic interneuron origin of schizophrenia pathophysiology. Neuropharmacology 62:1574-1583. CrossRef Medline

Papaleo F, Burdick MC, Callicott JH, Weinberger DR (2014) Epistatic interaction between COMT and DTNBP1 modulates prefrontal function in mice and in humans. Mol Psychiatry 19:311-316. CrossRef Medline

Pielage J, Fetter RD, Davis GW (2005) Presynaptic spectrin is essential for synapse stabilization. Curr Biol 15:918-928. CrossRef Medline

Purcell SM, Moran JL, Fromer M, Ruderfer D, Solovieff N, Roussos P, O’Dushlaine C, Chambert K, Bergen SE, Kähler A, Duncan L, Stahl E, Genovese G, Fernández E, Collins MO, Komiyama NH, Choudhary JS, Magnusson PK, Banks E, Shakir K, et al. (2014) A polygenic burden of rare disruptive mutations in schizophrenia. Nature 506:185-190. CrossRef Medline

Purcell SM, Wray NR, Stone JL, Visscher PM, O'Donovan MC, Sullivan PF, Sklar P (2009) Common polygenic variation contributes to risk of 
schizophrenia and bipolar disorder. Nature 460:748-752. CrossRef Medline

Rapoport JL, Giedd JN, Gogtay N (2012) Neurodevelopmental model of schizophrenia: update 2012. Mol Psychiatry 17:1228-1238. CrossRef Medline

Reeve SP, Bassetto L, Genova GK, Kleyner Y, Leyssen M, Jackson FR, Hassan BA (2005) The Drosophila fragile X mental retardation protein controls actin dynamics by directly regulating profilin in the brain. Curr Biol 15: 1156-1163. CrossRef Medline

Roos J, Kelly RB (1998) Dap160, a neural-specific Eps15 homology and multiple SH3 domain-containing protein that interacts with Drosophila dynamin. J Biol Chem 273:19108-19119. CrossRef Medline

Ryder PV, Vistein R, Gokhale A, Seaman MN, Puthenveedu MA, Faundez V (2013) The WASH complex, an endosomal Arp $2 / 3$ activator, interacts with the Hermansky-Pudlak syndrome complex BLOC-1 and its cargo phosphatidylinositol-4-kinase type ii alpha. Mol Biol Cell 24;2269-2284. CrossRef Medline

Sadanandappa MK, Blanco Redondo B, Michels B, Rodrigues V, Gerber B, VijayRaghavan K, Buchner E, Ramaswami M (2013) Synapsin function in GABA-ergic interneurons is required for short-term olfactory habituation. J Neurosci 33:16576-16585. CrossRef Medline

Starcevic M, Dell'Angelica EC (2004) Identification of snapin and three novel proteins (BLOS1, BLOS2, and BLOS3/reduced pigmentation) as subunits of biogenesis of lysosome-related organelles complex-1 (BLOC1). J Biol Chem 279:28393-28401. CrossRef Medline

Stefansson H, Ophoff RA, Steinberg S, Andreassen OA, Cichon S, Rujescu D, Werge T, Pietiläinen OP, Mors O, Mortensen PB, Sigurdsson E, Gustafsson $\mathrm{O}$, Nyegaard $\mathrm{M}$, Tuulio-Henriksson A, Ingason A, Hansen T, Suvisaari J, Lonnqvist J, Paunio T, Børglum AD, et al. (2009) Common variants conferring risk of schizophrenia. Nature 460:744-747. CrossRef Medline

Stefansson H, Meyer-Lindenberg A, Steinberg S, Magnusdottir B, Morgen K, Arnarsdottir S, Bjornsdottir G, Walters GB, Jonsdottir GA, Doyle OM, Tost H, Grimm O, Kristjansdottir S, Snorrason H, Davidsdottir SR, Gudmundsson LJ, Jonsson GF, Stefansdottir B, Helgadottir I, Haraldsson M, et al. (2014) CNVs conferring risk of autism or schizophrenia affect cognition in controls. Nature 505:361-366. CrossRef Medline

Straub RE, Jiang Y, MacLean CJ, Ma Y, Webb BT, Myakishev MV, HarrisKerr C, Wormley B, Sadek H, Kadambi B, Cesare AJ, Gibberman A, Wang X, O'Neill FA, Walsh D, Kendler KS (2002) Genetic variation in the 6p22.3 gene DTNBP1, the human ortholog of the mouse dysbindin gene, is associated with schizophrenia. Am J Hum Genet 71:337-348. CrossRef Medline

Sutton MA, Wall NR, Aakalu GN, Schuman EM (2004) Regulation of dendritic protein synthesis by miniature synaptic events. Science 304:19791983. CrossRef Medline

Talbot K, Eidem WL, Tinsley CL, Benson MA, Thompson EW, Smith RJ,
Hahn CG, Siegel SJ, Trojanowski JQ, Gur RE, Blake DJ, Arnold SE (2004) Dysbindin-1 is reduced in intrinsic, glutamatergic terminals of the hippocampal formation in schizophrenia. J Clin Invest 113:1353-1363. CrossRef Medline

Talbot K, Ong WY, Blake DJ, Tang D, Louneva N, Carlson GC, Arnold SE (2009) Dysbindin-1 and its protein family, with special attention to the potential role of dysbindin-1 in neuronal functions and the pathophysiology of schizophrenia. In: Handbook of neurochemistry and molecular neurobiology (Kantrowitz J, ed), pp 107-241. New York: Springer Science.

Tognin S, Viding E, McCrory EJ, Taylor L, O’Donovan MC, McGuire P, Mechelli A (2011) Effects of DTNBP1 genotype on brain development in children. J Child Psychol Psychiatry 52:1287-1294. CrossRef Medline

Twick I, Lee JA, Ramaswami M (2014) Olfactory habituation in Drosophilaodor encoding and its plasticity in the antennal lobe. Prog Brain Res 208:3-38. CrossRef Medline

van de Goor J, Ramaswami M, Kelly R (1995) Redistribution of synaptic vesicles and their proteins in temperature-sensitive shibire(ts1) mutant Drosophila. Proc Natl Acad Sci U S A 92:5739-5743. CrossRef Medline

Van Den Bogaert A, Schumacher J, Schulze TG, Otte AC, Ohlraun S, Kovalenko S, Becker T, Freudenberg J, Jönsson EG, Mattila-Evenden M, Sedvall GC, Czerski PM, Kapelski P, Hauser J, Maier W, Rietschel M, Propping P, Nöthen MM, Cichon S (2003) The DTNBP1 (dysbindin) gene contributes to schizophrenia, depending on family history of the disease. Am J Hum Genet 73:1438-1443. CrossRef Medline

Veitia RA, Bottani S, Birchler JA (2008) Cellular reactions to gene dosage imbalance: genomic, transcriptomic and proteomic effects. Trends Genet 24:390-397. CrossRef Medline

Williams LE, Blackford JU, Luksik A, Gauthier I, Heckers S (2013) Reduced habituation in patients with schizophrenia. Schizophr Res 151:124-132. CrossRef Medline

Wolf C, Jackson MC, Kissling C, Thome J, Linden DE (2011) Dysbindin-1 genotype effects on emotional working memory. Mol Psychiatry 16:145155. CrossRef Medline

Yang Q, He X, Yang L, Zhou Z, Cullinane AR, Wei A, Zhang Z, Hao Z, Zhang A, He M, Feng Y, Gao X, Gahl WA, Huizing M, Li W (2012) The BLOS1interacting protein KXD1 is involved in the biogenesis of lysosomerelated organelles. Traffic 13:1160-1169. CrossRef Medline

Zhang Q, Li W, Novak EK, Karim A, Mishra VS, Kingsmore SF, Roe BA, Suzuki T, Swank RT (2002) The gene for the muted (mu) mouse, a model for Hermansky-Pudlak syndrome, defines a novel protein which regulates vesicle trafficking. Hum Mol Genet 11:697-706. CrossRef Medline

Zhao L, Wang D, Wang Q, Rodal AA, Zhang YQ (2013) Drosophila cyfip regulates synaptic development and endocytosis by suppressing filamentous actin assembly. PLoS Genet 9:e1003450. CrossRef Medline 